\title{
A versatile fluorescent sensor array for platinum anti-cancer drug detection in biological fluids
}

Linda Mitchell, ${ }^{\dagger}$ Clara Shen,${ }^{\dagger}$ Hannah C. Timmins, ${ }^{\ddagger}$ Susanna B. Park, ${ }^{\ddagger}$ Elizabeth J. New ${ }^{\dagger,} \S^{*}$

$\dagger$ The University of Sydney, School of Chemistry, Sydney, NSW 2006, Australia

\$The University of Sydney, Brain \& Mind Centre, Sydney, NSW 2006, Australia

§The University of Sydney Nano Institute (Sydney Nano), The University of Sydney, NSW 2006, Australia

$\S$ Australian Research Council Centre of Excellence for Innovations in Peptide and Protein Science, The University of Sydney, NSW 2006, Australia 


\section{Synthesis}

For characterisation, ${ }^{1} \mathrm{H}$ NMR Spectra were recorded at $300 \mathrm{~K}$ using Bruker Avance 300 at a frequency of $300 \mathrm{MHz}{ }^{13} \mathrm{C} \mathrm{NMR}$ were recorded on Bruker Avance 400 at a frequency of 75 $\mathrm{MHz}$ low resolution ESI mass spectrometry was performed on a Bruker AmaZon SL ion trap mass spectrometer, and high-resolution mass spectrometry was performed on a Bruker Apex qE 7T Fourier Transform Ion Cyclotron Resonance mass spectrometer.

S1, S2, S4 and S6 were synthesized according to previously-reported procedures. ${ }^{1-4}$

\section{$\underline{\text { Synthesis of } \mathbf{S 3}}$}

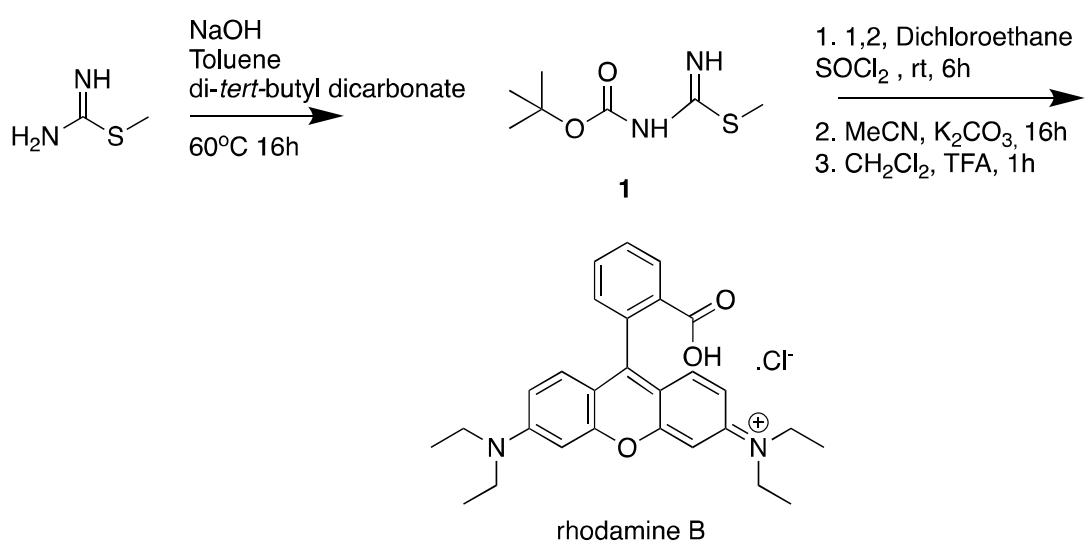

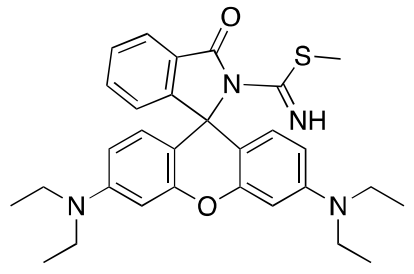

S3

In an adapted procedure ${ }^{5}$, to a solution of methyl carbamimidothioate hemisulfate $(500 \mathrm{mg}, 3.6$ $\mathrm{mmol})$ in $2 \mathrm{M} \mathrm{NaOH}(3 \mathrm{~mL})$ was added toluene $(5 \mathrm{~mL})$ and di-tert-butyl dicarbonate $(0.39 \mathrm{~g}$, $2.20 \mathrm{mmol})$. The reaction mixture was heated to $60^{\circ} \mathrm{C}$ and stirred for $16 \mathrm{~h}$. The organic layer was separated, washed with brine $(20 \mathrm{~mL})$, dried $\left(\mathrm{Na}_{2} \mathrm{SO}_{4}\right)$ and the solvent evaporated in vacuo to afford the product $(0.33 \mathrm{~g}, 1.7 \mathrm{mmol})$ as an off-white solid. ${ }^{1} \mathbf{H}$ NMR (300 $\left.\mathbf{~ M H z}, \mathbf{C D C l}\right)$ : $\delta 7.51$ (br s, $1 \mathrm{H}), 2.46$ (s, $3 \mathrm{H}), 1.51$ (s, 9 H). ${ }^{\mathbf{1 3}} \mathbf{C}$ NMR (75 MHz, CDCl 3$): \delta 173.0,161.7$, 79.9, 28.2, 13.5. LRMS (ESI): calculated for $[\mathrm{M}+\mathrm{H}]^{+}\left(\mathrm{C}_{7} \mathrm{H}_{14} \mathrm{~N}_{2} \mathrm{O}_{2} \mathrm{~S}\right) \mathrm{m} / z: 191.0$ found $[\mathrm{M}+\mathrm{H}]^{+}$ : 191.0, found $[\mathrm{M}-\mathrm{t}-\mathrm{Bu}+\mathrm{H}]^{+}: 135.0$.

A solution of Rhodamine B (100mg, $0.21 \mathrm{mmol})$ and thionyl chloride $(0.30 \mathrm{~mL}, 4.11 \mathrm{mmol})$ were stirred at room temperature for $2 \mathrm{~h}$. The acid chloride was precipitated in diethyl ether, filtered and washed with ether. The viscous oil was dissolved in $10 \mathrm{~mL}$ dry MeCN and added dropwise to a solution of boc-protected 2-methyl-2-thiopseudourea ( $45 \mathrm{mg}, 0.24 \mathrm{mmol}$ ), $\mathrm{K}_{2} \mathrm{CO}_{3}(150 \mathrm{mg}, 1.09 \mathrm{mmol})$ in $\mathrm{MeCN}(3 \mathrm{~mL})$. The reaction mixture was stirred at room temperature for $16 \mathrm{~h}$. The product was filtered through a silica plug (50:50 EtOAc:hexane) and the solvent evaporated in vacuo to afford a violet oil. The product was redissolved in $\mathrm{CH}_{2} \mathrm{Cl}_{2}$ $(6 \mathrm{~mL})$ and trifluoroacetic acid was added $(1.00 \mathrm{~mL})$. The reaction was stirred at room temperature for $1 \mathrm{~h}$, the solvent removed in vacuo and the product was purified using flash chromatography $\left(\mathrm{SiO}_{2}, 2: 98 \mathrm{MeOH}: \mathrm{CH}_{2} \mathrm{Cl}_{2}\right.$ ) to yield a light pink solid (48 $\mathrm{mg}, 0.093 \mathrm{mmol}$ ). ${ }^{1} \mathbf{H}$ NMR (500 MHz; CDCl $): \delta 7.93(\mathrm{~d}, \mathrm{~J}=7.5 \mathrm{~Hz}, 1 \mathrm{H}), 7.47(\mathrm{td}, \mathrm{J}=7.4 \mathrm{~Hz}, 1.1 \mathrm{~Hz}, 1 \mathrm{H})$, $7.42(\mathrm{td}, \mathrm{J}=7.5 \mathrm{~Hz}, 1.0 \mathrm{~Hz}, 1 \mathrm{H}), 7.01(\mathrm{~d}, \mathrm{~J}=7.5 \mathrm{~Hz}, 1 \mathrm{H}), 6.52(\mathrm{~d}, \mathrm{~J}=8.8 \mathrm{~Hz}, 2 \mathrm{H}), 6.39$ (d, J $=2.6 \mathrm{~Hz}, 2 \mathrm{H}), 6.26(\mathrm{dd}, \mathrm{J}=8.9 \mathrm{~Hz}, 2.6 \mathrm{~Hz}, 2 \mathrm{H}), 3.33(\mathrm{q}, \mathrm{J}=7.2 \mathrm{~Hz}, 8 \mathrm{H}), 2.13(\mathrm{~s}, 3 \mathrm{H}), 1.16(\mathrm{t}$, $\mathrm{J}=7.3 \mathrm{~Hz}, 12 \mathrm{H}) .{ }^{13} \mathbf{C}$ NMR (125 MHz, CDCl3): $\delta$ 12.8, 14.3, 44.4, 67.0, 97.9, 106.6, 107.9, $123.8,124.3,127.9,128.1,128.4,128.5,134.5,149.0,152.9,154.2,169.2$; HRMS (ESI): calculated for $[\mathrm{M}+\mathrm{H}]^{+}\left(\mathrm{C}_{30} \mathrm{H}_{33} \mathrm{~N}_{4} \mathrm{O}_{2} \mathrm{~S}\right) \mathrm{m} / z: 514.2402$ found $[\mathrm{M}+\mathrm{H}]^{+},:$514.2477. 


\section{Design of fluorescent sensor array}

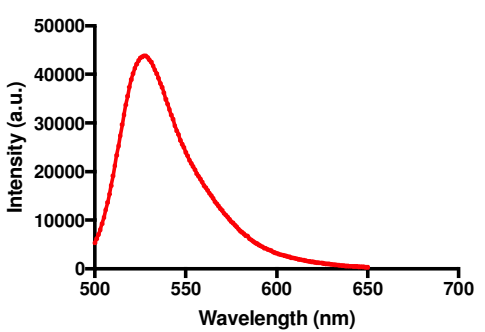

S4

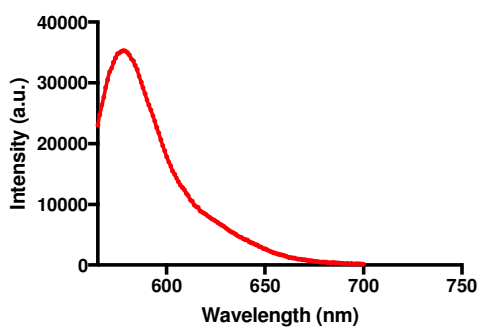

S2

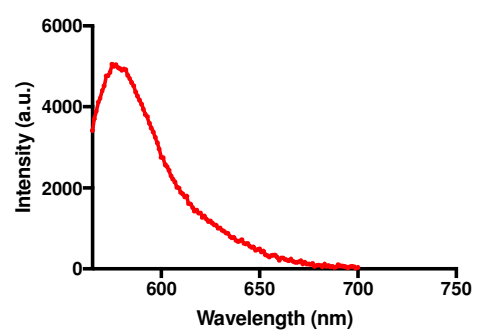

S5

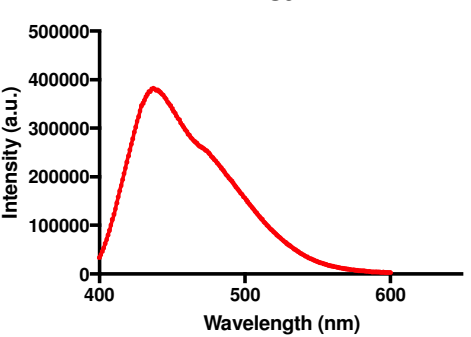

S3

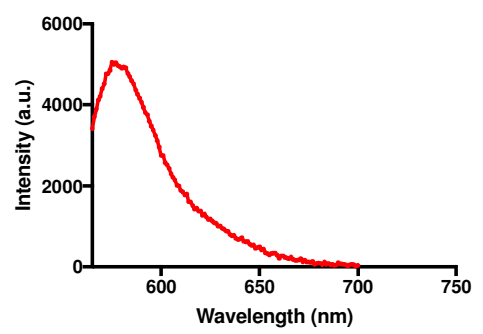

S6

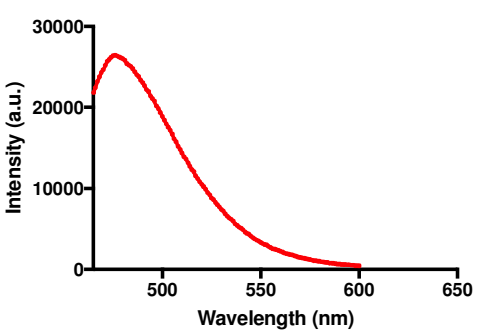

Figure S1. Fluorescence emission spectra obtained by S1-6 $(200 \mu \mathrm{M})$ in HEPES buffer (20 $\mathrm{mM}, \mathrm{pH}$ 7.4). Excitation wavelengths were; S1 - $380 \mathrm{~nm}, \mathbf{S 2 - 4}-545 \mathrm{~nm}, \mathbf{S 5}$ - $280 \mathrm{~nm}$ and S6 $-445 \mathrm{~nm}$. 


\section{Discrimination of platinum from other metals}

a)

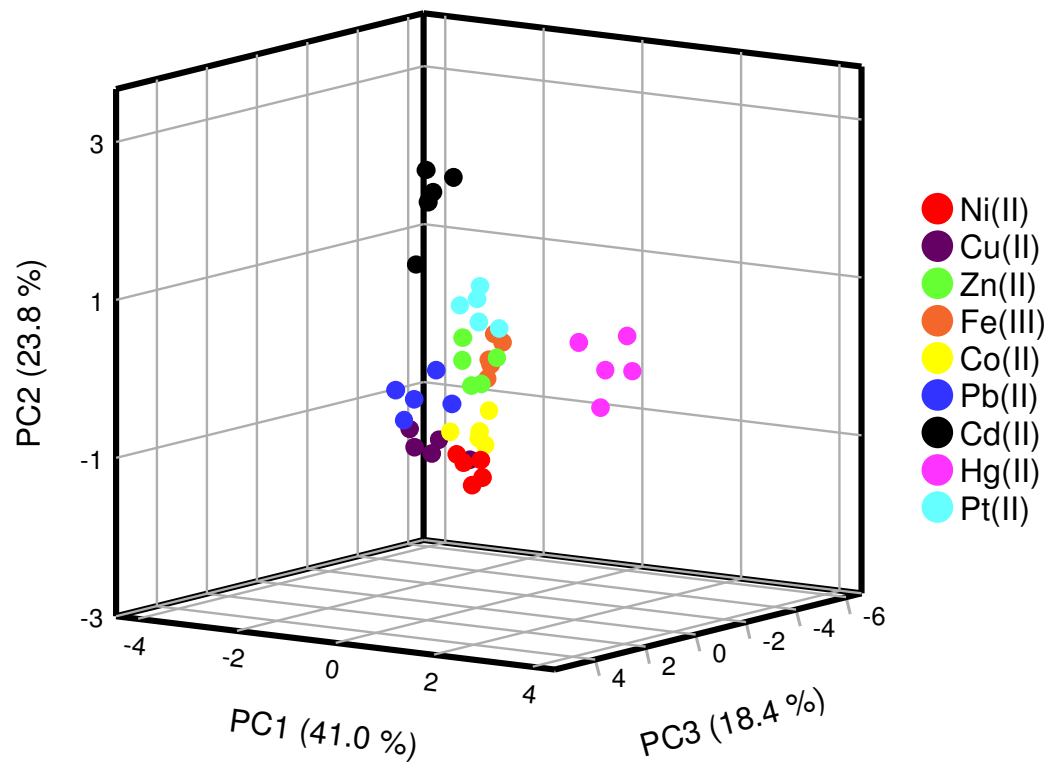

b)

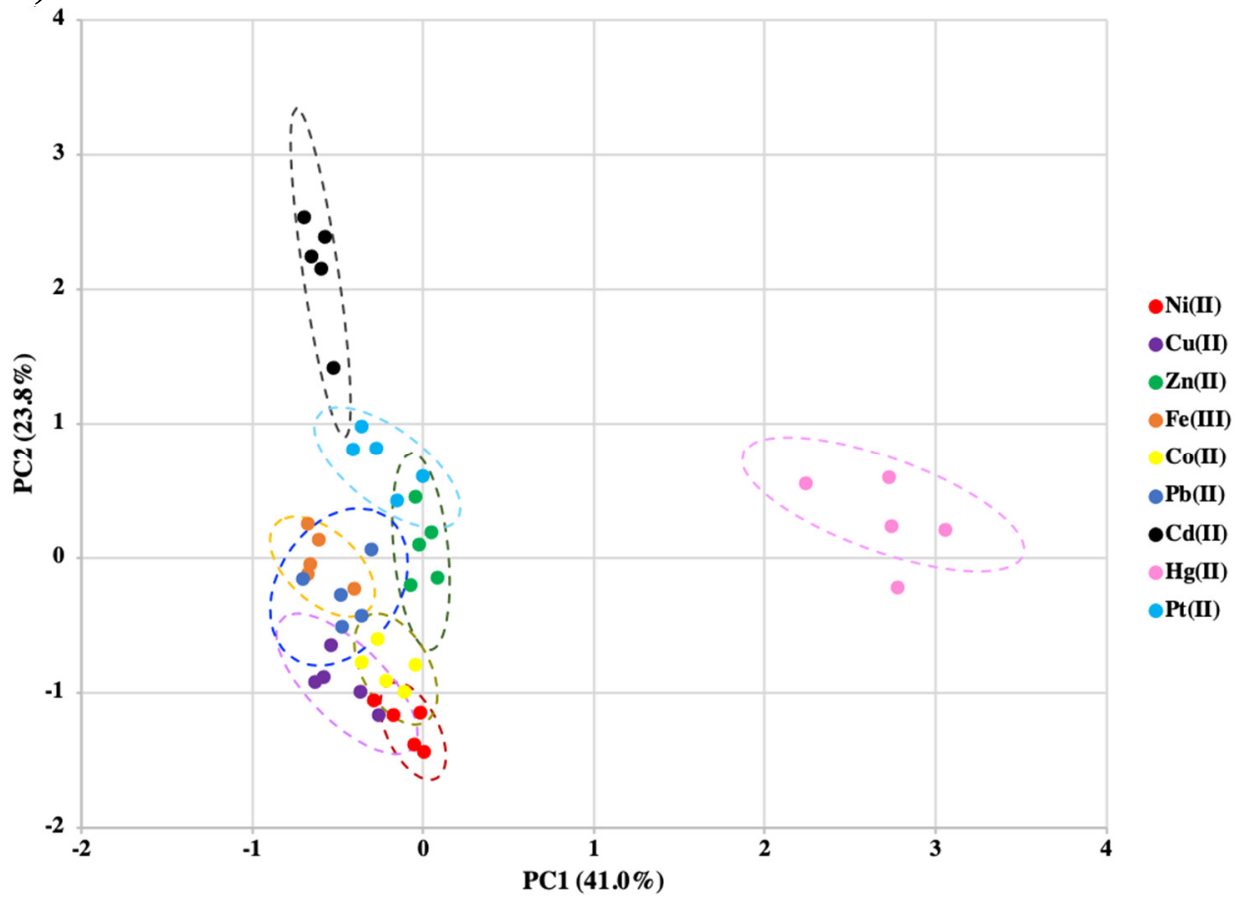

Figure S2. a) PCA score plot of fluorescence response pattern $\left(\mathrm{I} / \mathrm{I}_{0}\right)$ of S1-6 $(10 \mu \mathrm{M})$ with a variety of metal ions $(50 \mu \mathrm{M})$ in DMF $(2 \% \mathrm{v} / \mathrm{v})$ diluted in HEPES buffer $(20 \mathrm{mM}, \mathrm{pH} 7.4)$. $83.2 \%$ of the variance in response explained by the first three components PC1, PC2 and PC3. b) The first two components PC1 and PC2 with $95 \%$ confidence ellipses. 
Table S1. PCA correlation matrix of the six sensors responding to 9 metal ions.

\begin{tabular}{|l|l|l|l|l|l|l|}
\hline & S5 & S4 & S3 & S2 & S1 & S6 \\
\hline S5 & 1 & 0.428 & 0.681 & 0.424 & -0.098 & 0.202 \\
\hline S4 & 0.428 & 1 & 0.038 & 0.994 & -0.124 & 0.198 \\
\hline S3 & 0.681 & 0.038 & 1 & 0.026 & 0.072 & -0.051 \\
\hline S2 & 0.424 & 0.994 & 0.026 & 1 & -0.122 & 0.215 \\
\hline S1 & -0.098 & -0.124 & 0.072 & -0.122 & 1 & 0.111 \\
\hline S6 & 0.202 & 0.198 & -0.051 & 0.215 & 0.111 & 1 \\
\hline
\end{tabular}

a)

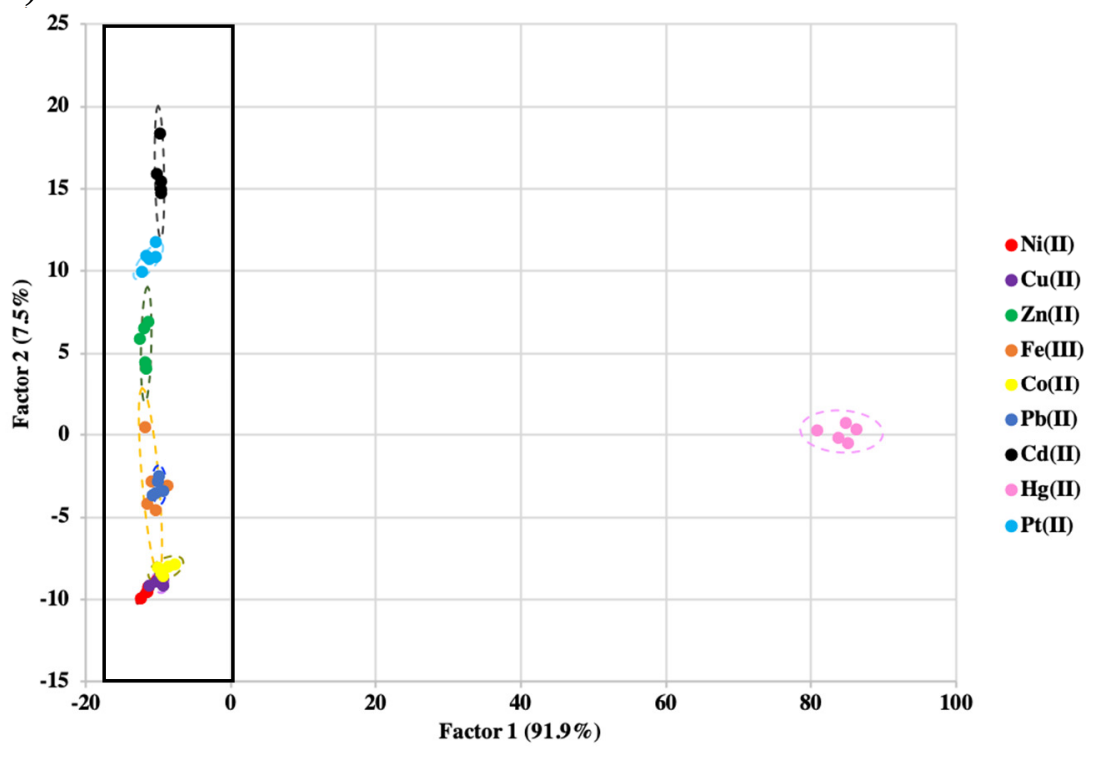

b)

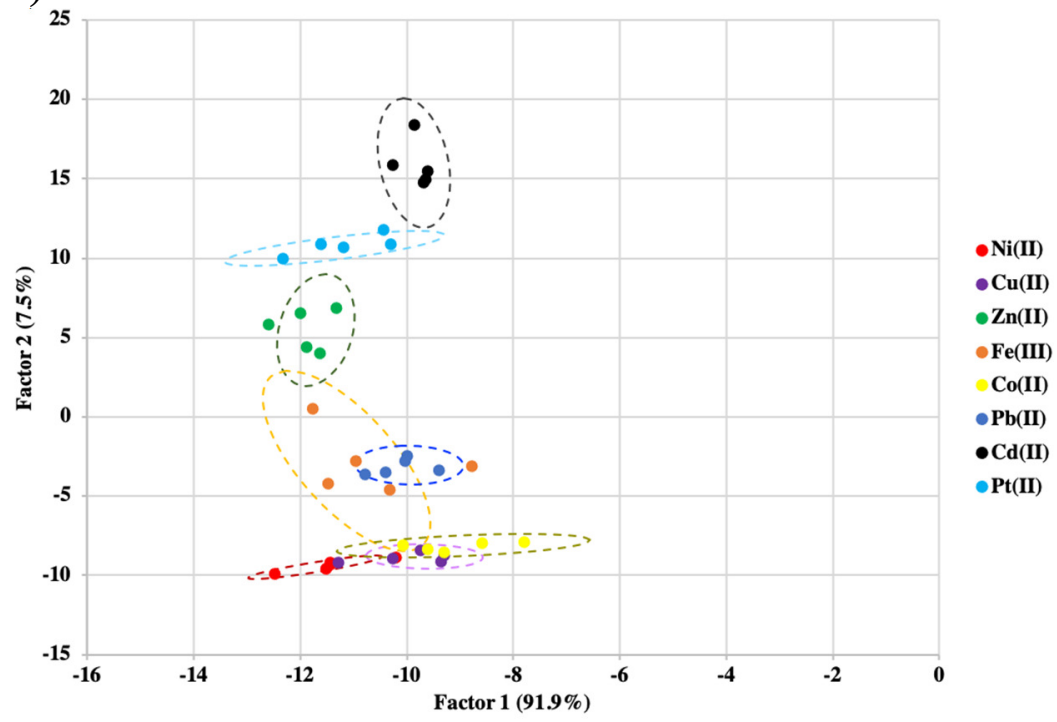

Figure S3. Fluorescence response pattern of S1-6 $(10 \mu \mathrm{M})$ with nine metal ions $(50 \mu \mathrm{M})$ in HEPES buffer (20 mM, pH 7.4) and DMF (2\% v/v) presented as a) a two-dimensional LDA score plot and b) an expansion of the region indicated on the upper plot, with $95 \%$ confidence ellipses. 


\section{Discrimination of platinum complexes}

a)<smiles>N[Pb](N)(Cl)Cl</smiles>

e)<smiles>N[P+](N)(N)Cl</smiles>

b)<smiles>N[PH3+](N)Cl</smiles>

f)<smiles>Cl[Pt](Cl)(Cl)Cl</smiles>

c)<smiles>NCCN[Pb](Cl)(Cl)Cl</smiles>

g)<smiles>O=C1N[Pb]2(NC3CCCCC3N2)O1</smiles>

d)<smiles>N[PH3+](N)c1cc2ccccc2c2ccccc12</smiles>

h)<smiles>N[PH3+](N)Cl</smiles>

Figure S4. Platinum complexes; a) cisplatin, b) transplatin, c) $\left[\mathrm{PtCl}_{2}(\mathrm{en})\right]$, d) phenanthriplatin, e) $\left.\left[\mathrm{PtCl}\left(\mathrm{NH}_{3}\right)_{3}\right] \mathrm{Cl}, \mathrm{f}\right) \mathrm{K}_{2}\left[\mathrm{PtCl}_{4}\right]$, g) oxaliplatin, h) pyriplatin.

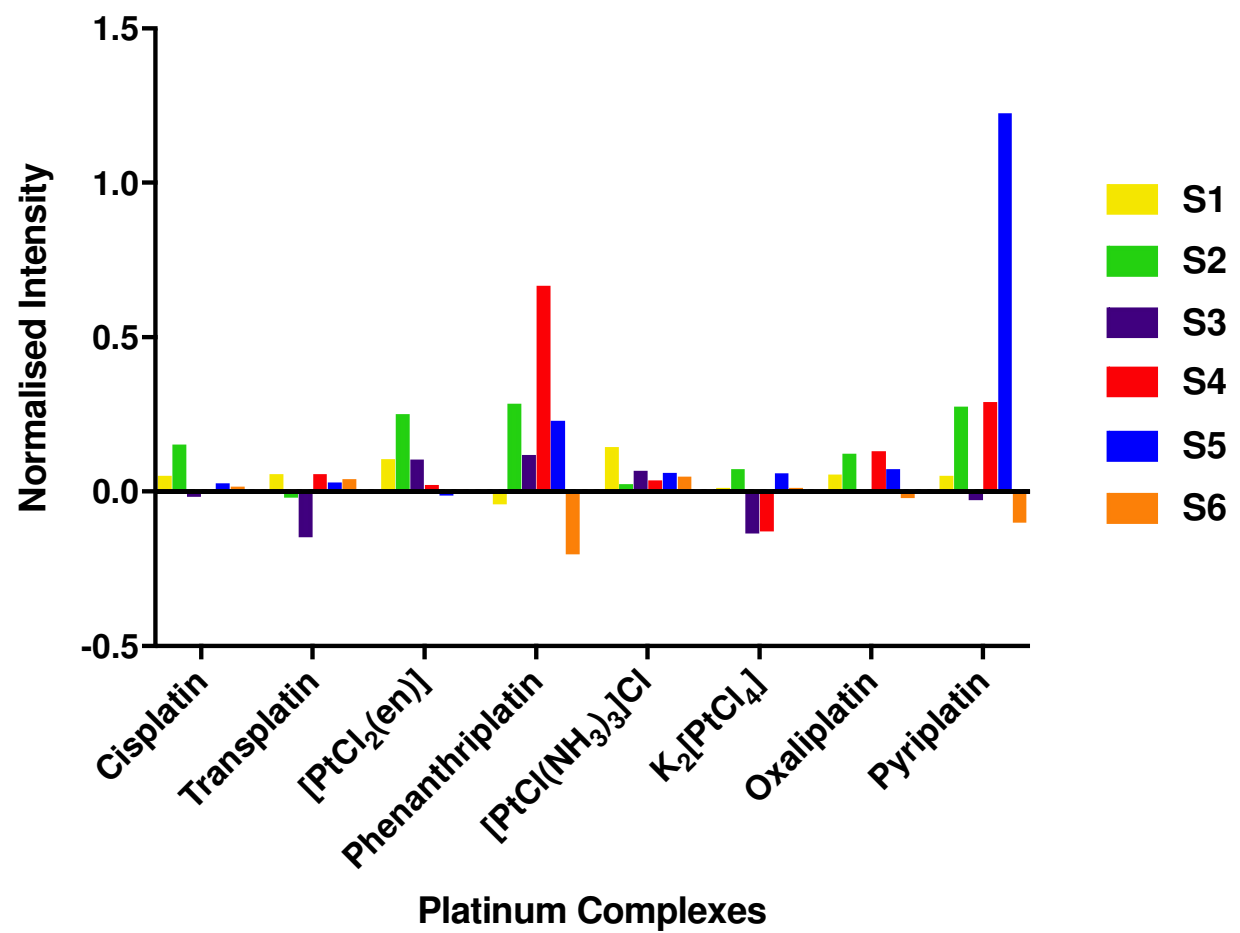

Figure S5. Normalised fluorescence response pattern $\left(\mathrm{I} / \mathrm{I}_{0}-1\right)$ of S1-6 $(200 \mu \mathrm{M})$ in response to 8 platinum complexes $(200 \mu \mathrm{M})$ in DMF $(2 \% \mathrm{v} / \mathrm{v})$ and diluted in HEPES buffer $(20 \mathrm{mM}$, $\mathrm{pH} 7.4)$. 
a)

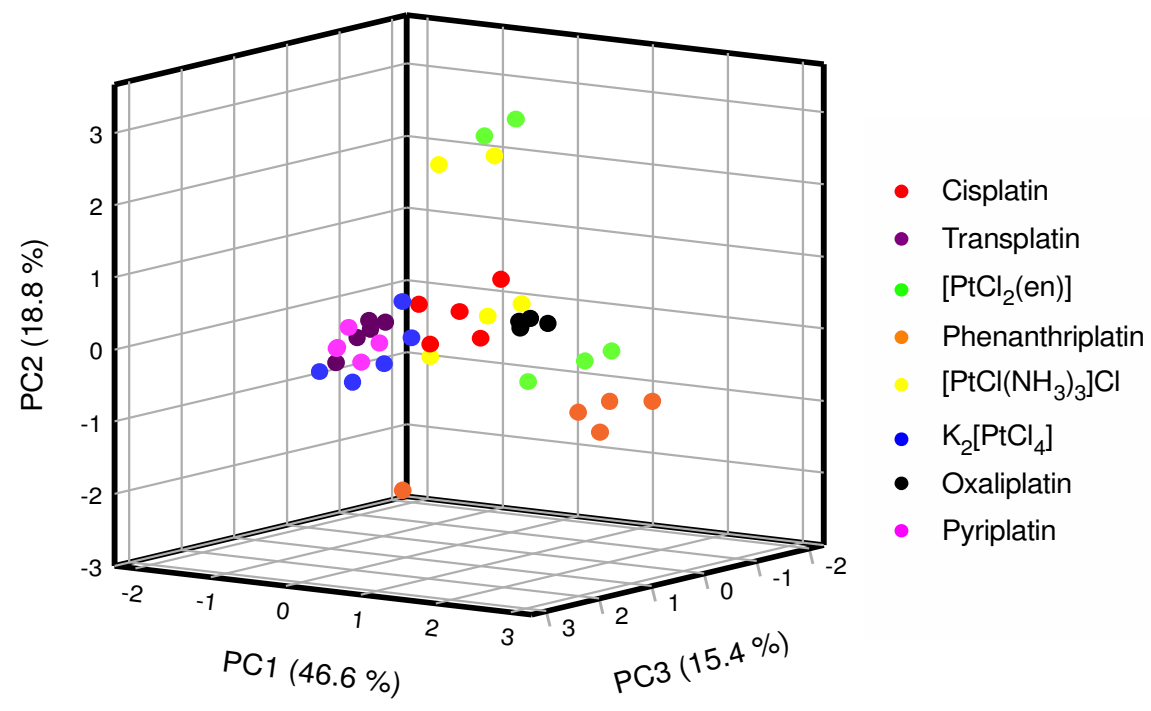

b)

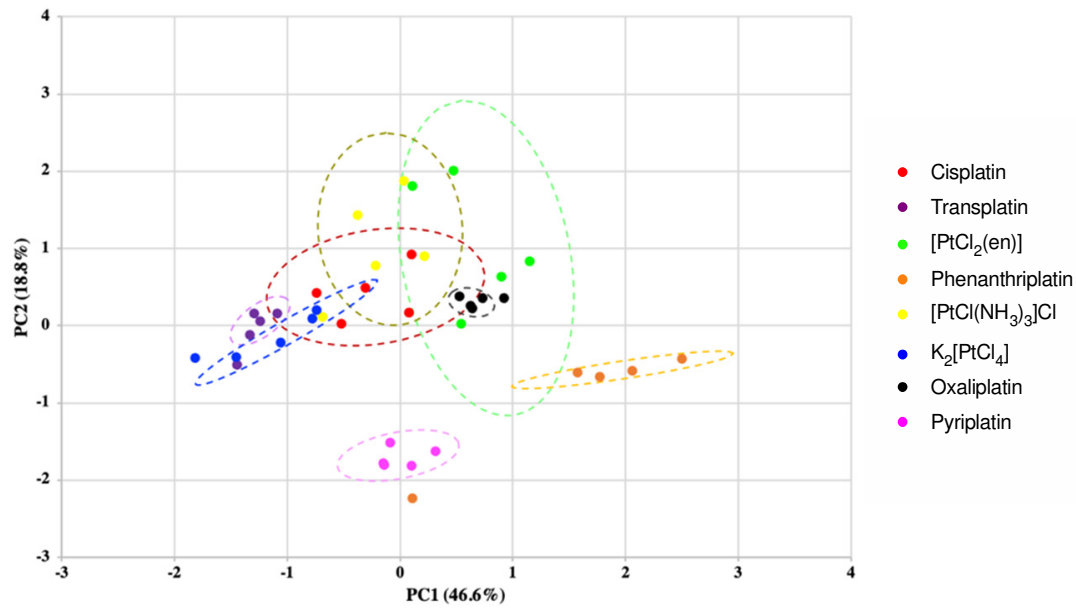

Figure S6. PCA of the fluorescence response pattern $\left(\mathrm{I} / \mathrm{I}_{0}\right)$ of S1-6 $(200 \mu \mathrm{M})$ in response to 8 platinum complexes $(200 \mu \mathrm{M})$ in DMF $(2 \% \mathrm{v} / \mathrm{v})$ and HEPES buffer $(20 \mathrm{mM}, \mathrm{pH} 7.4) .86 .2 \%$ of the variance in response explained by a) the first three components PC1, PC2 and PC 3 and b) the first two components PC1 and PC2 with $95 \%$ confidence ellipses.

Table S2. PCA correlation matrix of the six sensors responding to 8 platinum complexes.

\begin{tabular}{|l|l|l|l|l|l|l|}
\hline & S5 & S4 & S3 & S2 & S1 & S6 \\
\hline S5 & 1 & -0.088 & -0.104 & -0.271 & -0.12 & 0.419 \\
\hline S4 & -0.088 & 1 & 0.559 & 0.542 & 0.224 & -0.613 \\
\hline S3 & -0.104 & 0.559 & 1 & 0.469 & -0.055 & -0.379 \\
\hline S2 & -0.271 & 0.542 & 0.469 & 1 & 0.303 & -0.806 \\
\hline S1 & -0.12 & 0.224 & -0.055 & 0.303 & 1 & -0.33 \\
\hline S6 & 0.419 & -0.613 & -0.379 & -0.806 & -0.33 & 1 \\
\hline
\end{tabular}




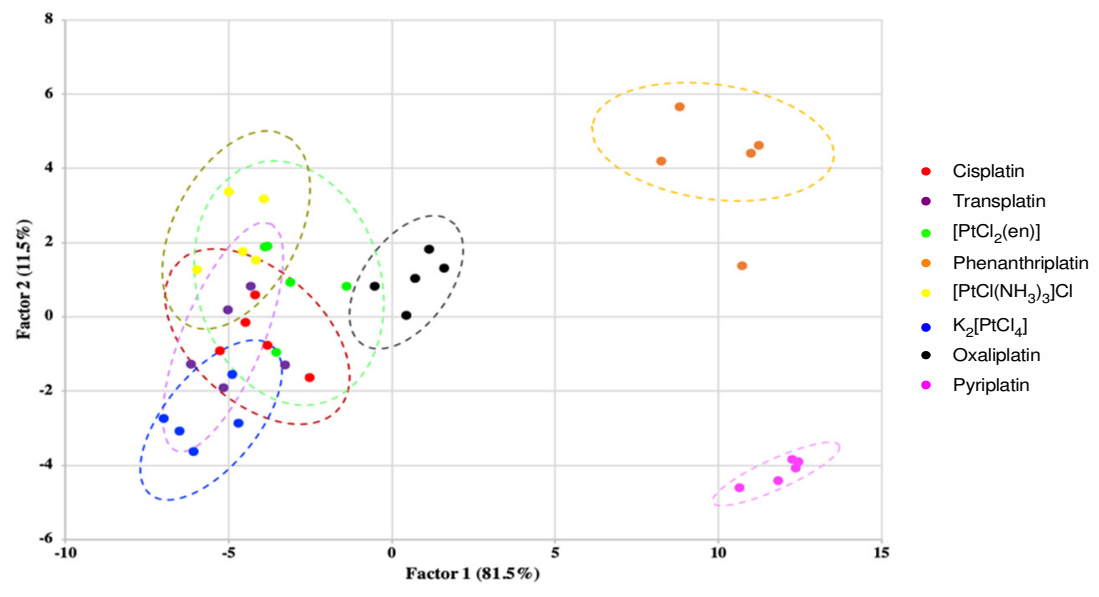

Figure S7. The fluorescence response pattern $\left(\mathrm{I} / \mathrm{I}_{0}\right)$ of S1-6 $(200 \mu \mathrm{M})$ with 8 platinum complexes $(200 \mu \mathrm{M})$ in HEPES buffer $(20 \mathrm{mM}, \mathrm{pH} 7.4)$ and DMF $(2 \% \mathrm{v} / \mathrm{v})$ presented as a twodimensional LDA score plot with $95 \%$ confidence intervals.

a)

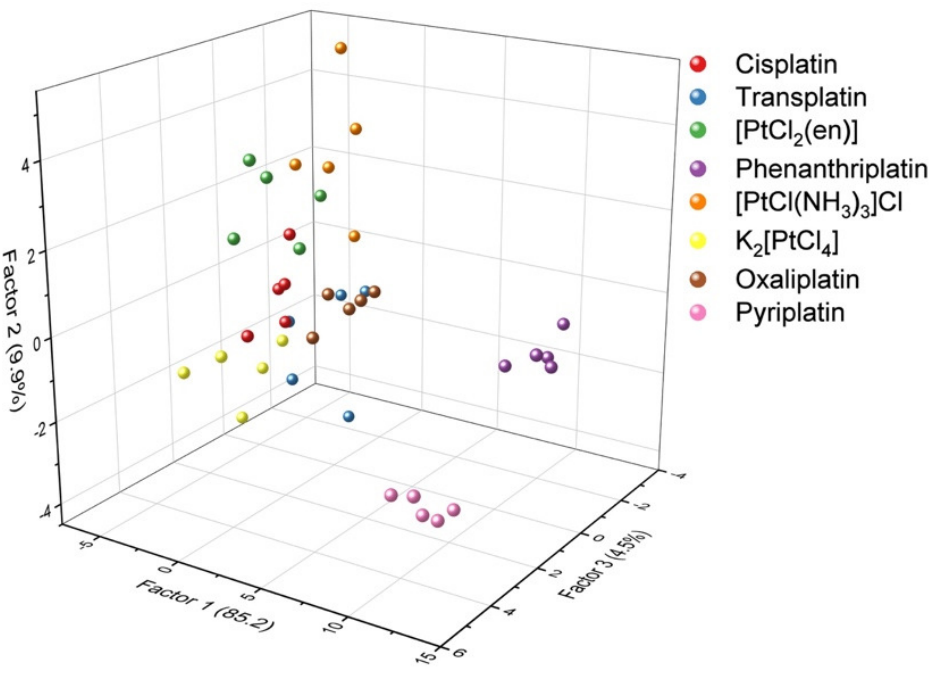

b)

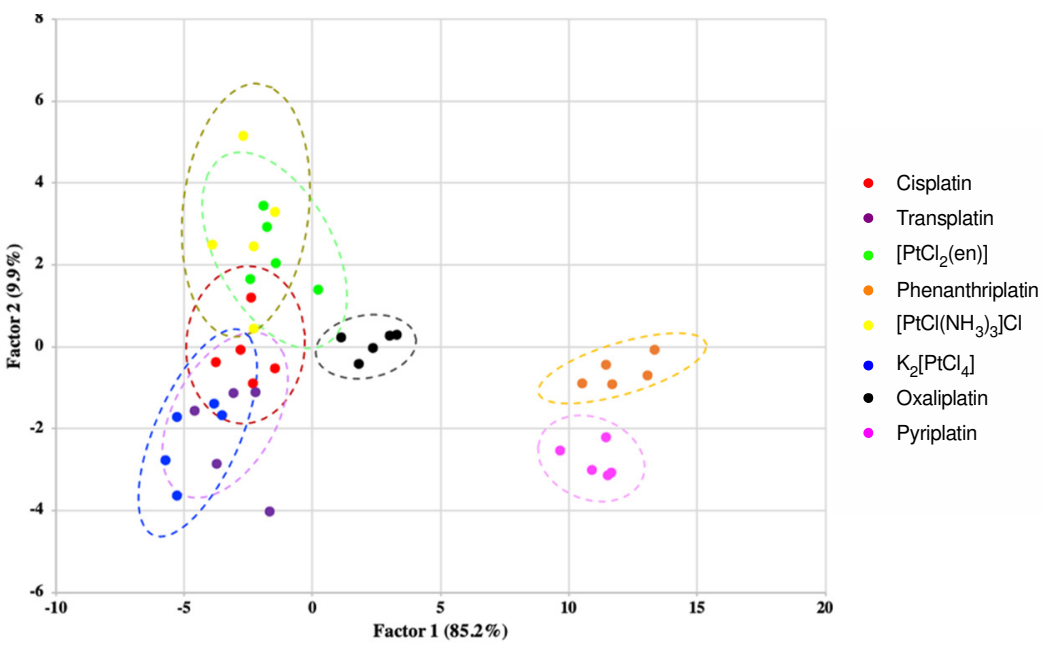

Figure S8. The fluorescence response pattern $\left(\mathrm{I} / \mathrm{I}_{0}\right)$ of S1-6 $(200 \mu \mathrm{M})$ with 8 platinum complexes $(200 \mu \mathrm{M})$ in HEPES buffer $(20 \mathrm{mM}, \mathrm{pH} 7.4)$ and DMF (2\% v/v). LDA containing ungrouped replicates of pyriplatin is presented as a) a three-dimensional score plot of the first three factors obtained of and b) the first two factors with $95 \%$ confidence ellipses. 


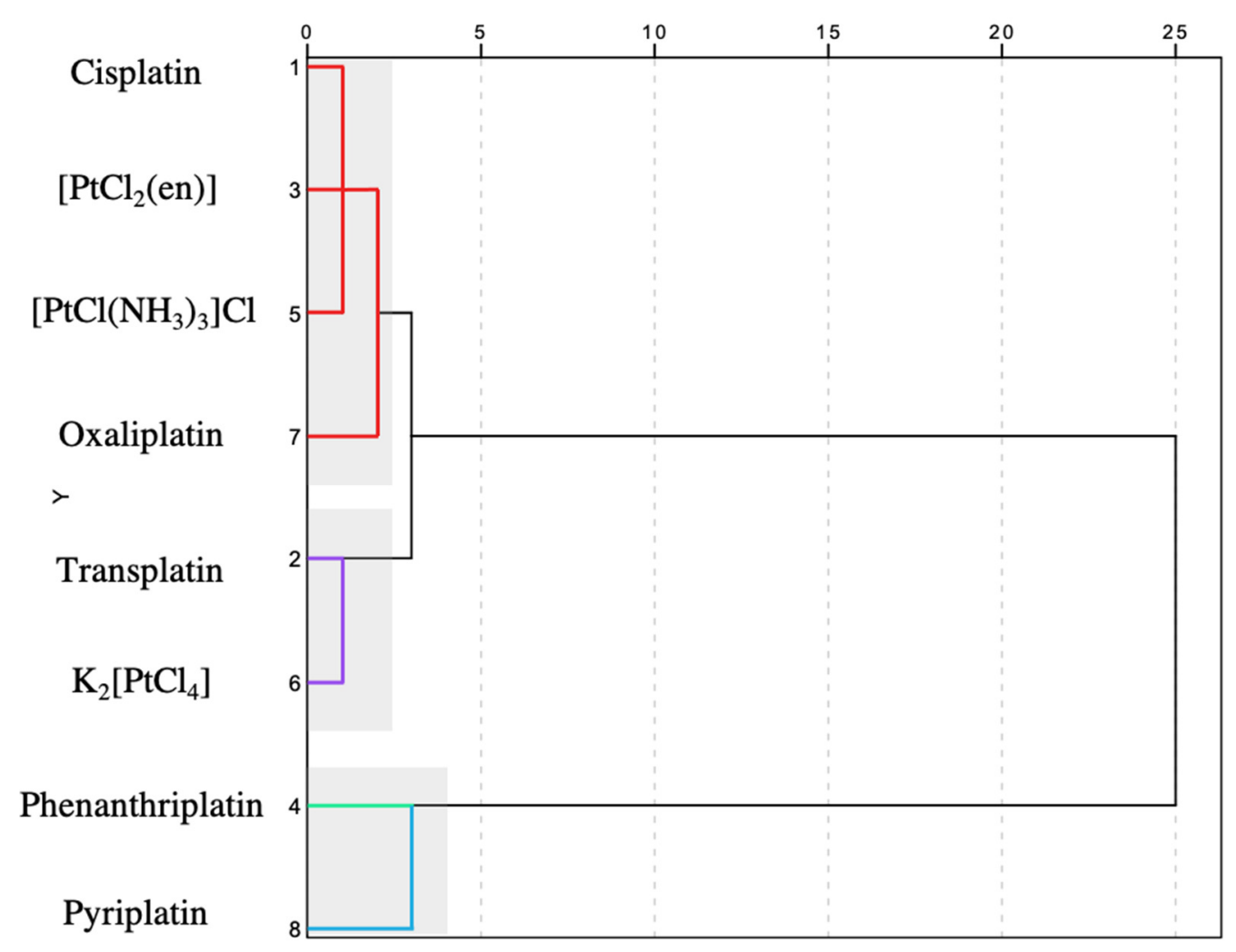

Figure S9. The fluorescence response pattern $\left(\mathrm{I} / \mathrm{I}_{0}\right)$ of S1-6 $(200 \mu \mathrm{M})$ with 8 platinum complexes $(200 \mu \mathrm{M})$ in HEPES buffer $(20 \mathrm{mM}, \mathrm{pH} 7.4)$ and DMF $(2 \% \mathrm{v} / \mathrm{v})$. HCA dendrogram is based on the squared Euclidean distance using Ward's method, created using a data set of responses from averaged replicates of each sensor/analyte. Grey areas represent three major clusters of various platinum configurations. 


\section{Monitoring platinum drugs spiked in human plasma}

a)

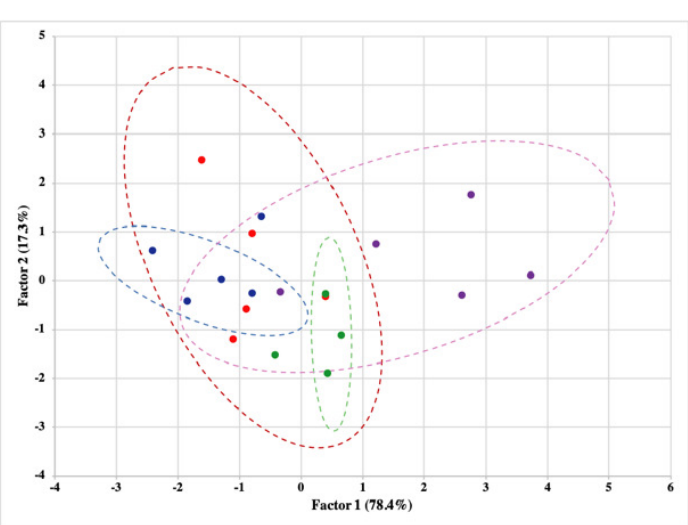

c)

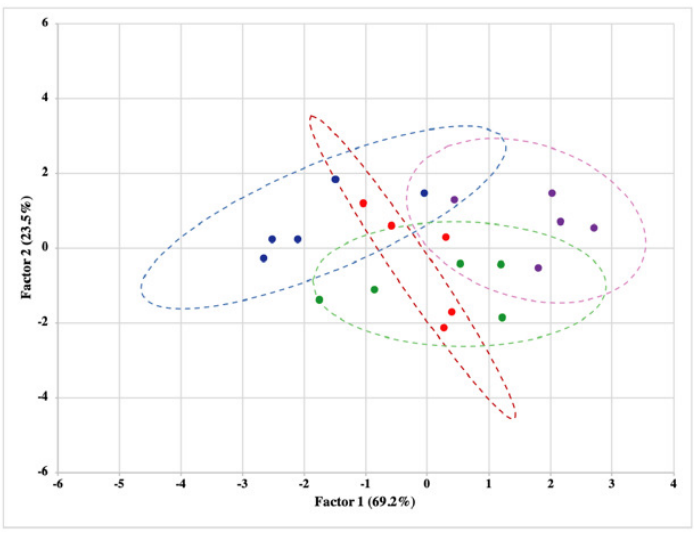

b)

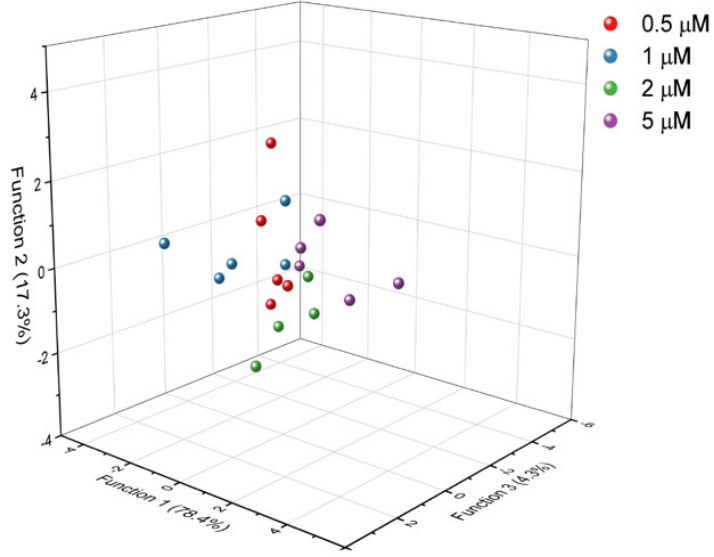

d)

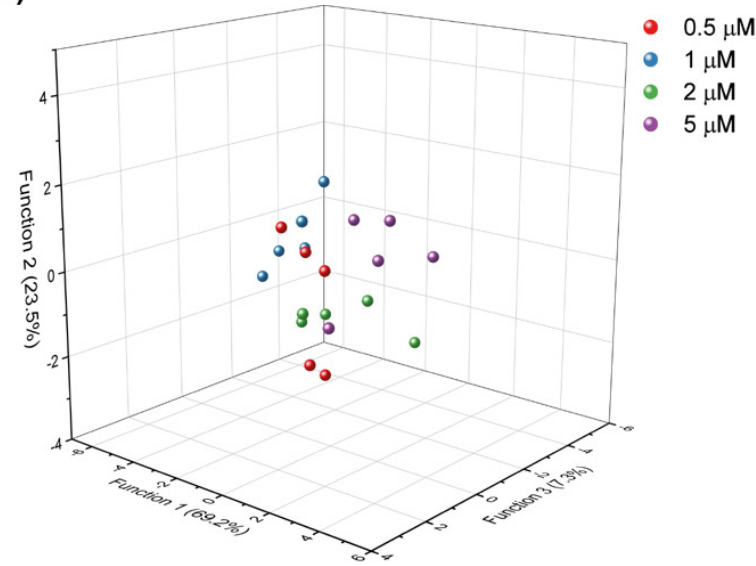

Figure S10. The fluorescence response pattern $\left(\mathrm{I} / \mathrm{I}_{0}\right)$ of S1-6 $(10 \mu \mathrm{M})$ in DMF $(4 \% \mathrm{v} / \mathrm{v})$ diluted in PBS buffer $(20 \mathrm{mM}, \mathrm{pH} 7.4,46 \% \mathrm{v} / \mathrm{v})$ and human plasma $(50 \% \mathrm{v} / \mathrm{v})$ using 6 fluorescence measurements. Cisplatin data is presented as a) the first two LDA factors with $95 \%$ confidence ellipses and b) a three-dimensional LDA score plot. Oxaliplatin data is presented as c) the first two LDA factors with $95 \%$ confidence ellipses and d) a three-dimensional LDA score plot.

Table S3. 24 fluorescence measurements collected during array analysis (4 excitation x 6 sensors).

\begin{tabular}{|l|l|l|l|l|l|l|}
\hline $\begin{array}{l}\text { Excitation } \\
\text { measurement }\end{array}$ & S1 & S2 & S3 & S4 & S5 & S6 \\
\hline $380 \mathrm{~nm}$ & & & & & & \\
\hline $445 \mathrm{~nm}$ & & & & & & \\
\hline $480 \mathrm{~nm}$ & & & & & & \\
\hline $545 \mathrm{~nm}$ & & & & & & \\
\hline
\end{tabular}

Blue: no fluorescence emission at these excitations.

Red: measurements removed during optimisation studies.

Yellow: 8 additional measurements used in clinical studies.

Green: 6 original measurements used in metal and platinum complexes array. 

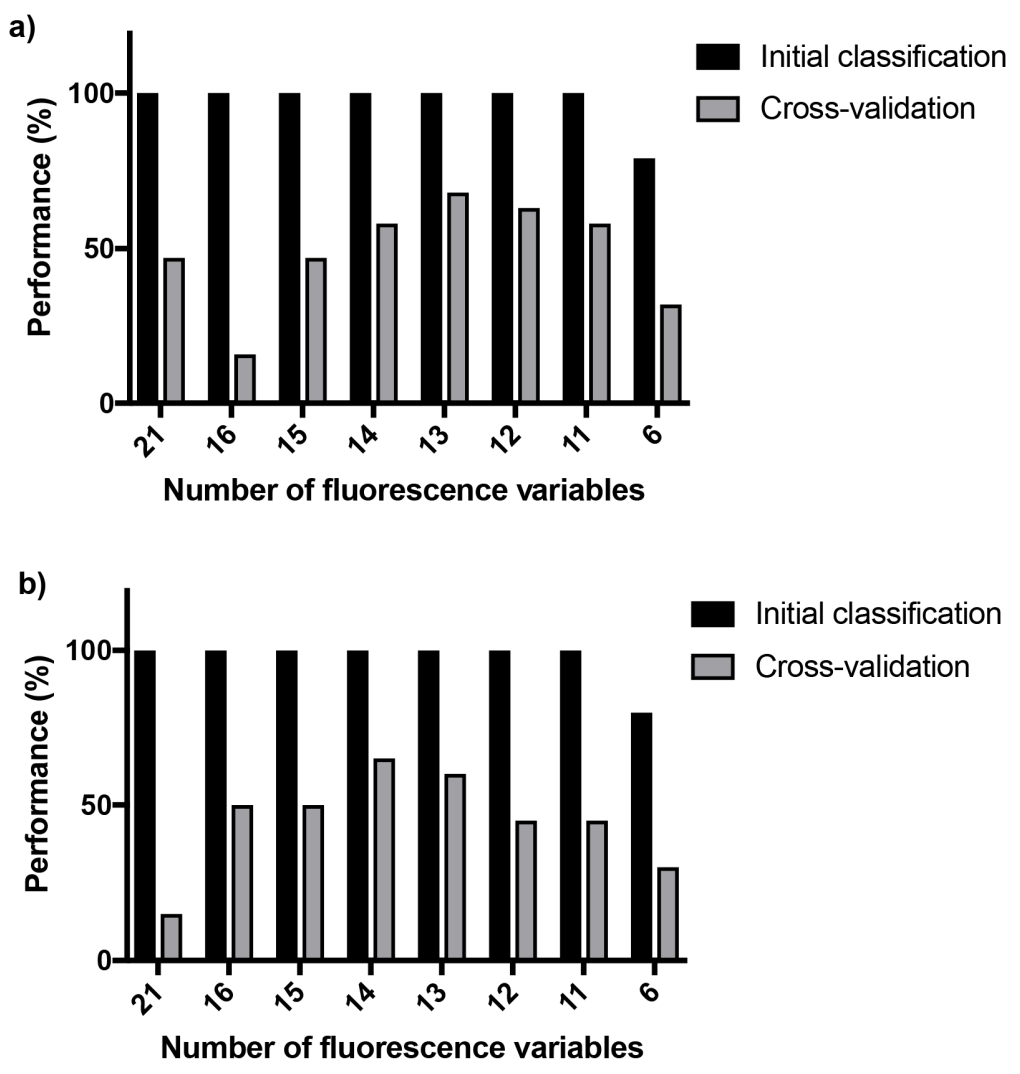

Figure S11. Performance graphs comparing classification accuracy (with cross-validation) to the number of fluorescence measurements used during LDA for a) cisplatin and b) oxaliplatin. 
a)

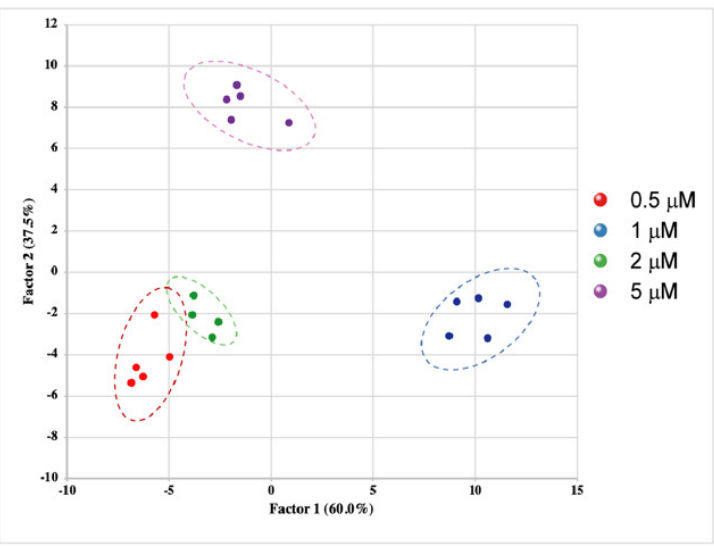

b)

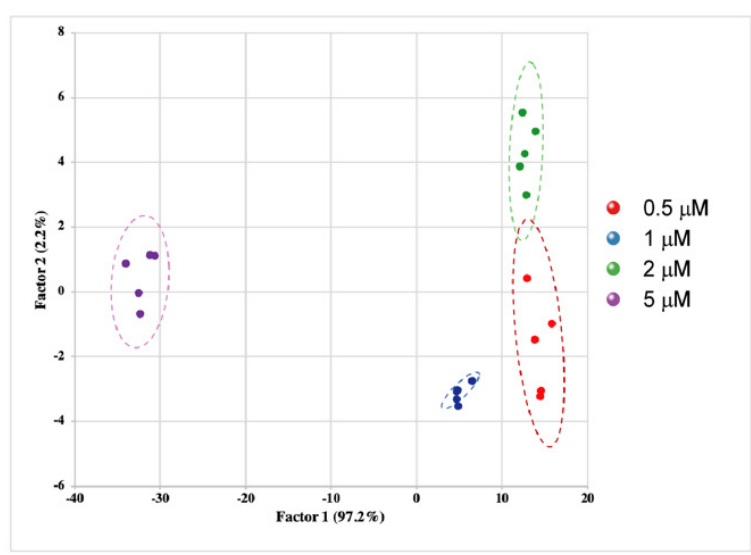

c)

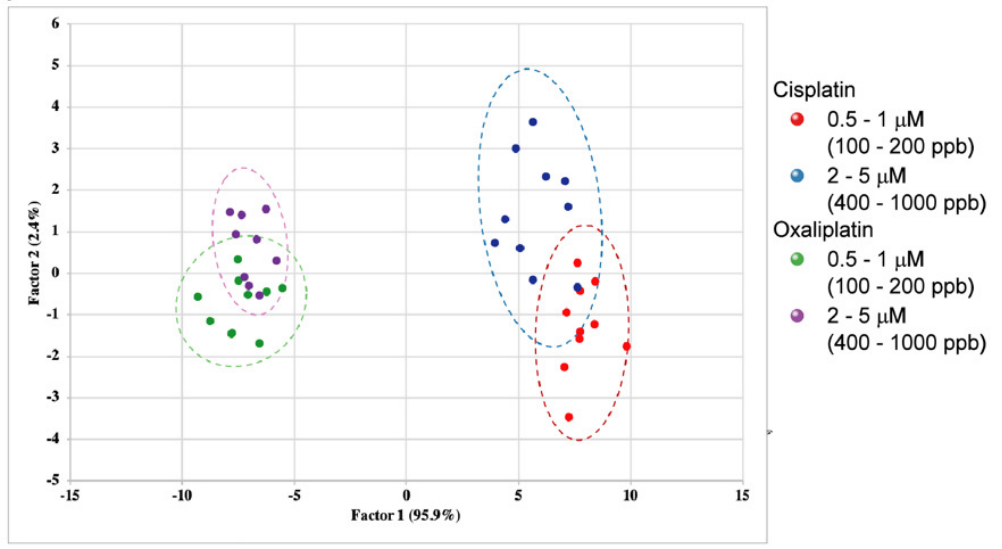

Figure S12. The fluorescence response pattern $\left(\mathrm{I} / \mathrm{I}_{0}\right)$ of S1-6 $(10 \mu \mathrm{M})$ in $\mathrm{DMF}(4 \% \mathrm{v} / \mathrm{v})$ diluted in PBS buffer (20 mM, pH 7.4, $46 \% \mathrm{v} / \mathrm{v})$ and human plasma (50\% v/v) using 14 fluorescence measurements. a) Cisplatin at 4 concentrations presented as the first two LDA factors with $95 \%$ confidence ellipses, b) oxaliplatin at 4 concentrations presented as the first two LDA factors with $95 \%$ confidence ellipses and c) two concentrations ranges of both cisplatin and oxaliplatin presented as the first two LDA factors with $95 \%$ confidence ellipses. 
Table S4. ICP-MS data for 73 clinical human plasma samples. Values in the table are original concentrations calculated by converting raw counts to ppb using a calibration curve. Later analysis involved diluting samples in buffer media and these calculated concentrations are reflected in later tables.

\begin{tabular}{|c|c|c|c|c|}
\hline $\begin{array}{l}\text { Drug - } \\
\text { patient no. }\end{array}$ & Sample no. & Pt(II) ppb & $\begin{array}{l}\text { Standard } \\
\text { Deviation (ppb) }\end{array}$ & Time point in treatment \\
\hline \multirow{2}{*}{$\begin{array}{l}\text { Blank } \\
\text { (no treatment) }\end{array}$} & - & -0.23 & 0.09 & - \\
\hline & - & -0.34 & 0.01 & - \\
\hline \multirow[t]{3}{*}{ Oxaliplatin-1 } & 1 & 146 & 6 & Cycle 1 \\
\hline & 2 & 226 & 5 & Cycle 6 \\
\hline & 3 & 74 & 5 & 42 days post-completion \\
\hline \multirow[t]{3}{*}{ Oxaliplatin-2 } & 4 & 278 & 1 & Cycle 2 \\
\hline & 5 & 256 & 30 & Cycle 6 \\
\hline & 6 & 49 & 4 & 55 days post-completion \\
\hline \multirow[t]{3}{*}{ Oxaliplatin-3 } & 7 & 108 & 0 & Cycle 1 \\
\hline & 8 & 126 & 7 & Cycle 3 \\
\hline & 9 & 406 & 11 & Cycle 5 \\
\hline \multirow{3}{*}{ Oxaliplatin-4 } & 10 & 123 & 2 & Cycle 1 \\
\hline & 11 & 158 & 6 & Cycle 6 \\
\hline & 12 & 139 & 3 & 28 days post-completion \\
\hline \multirow[t]{3}{*}{ Oxaliplatin -5} & 13 & 187 & 6 & Cycle 1 \\
\hline & 14 & 144 & 3 & Cycle 6 \\
\hline & 15 & 127 & 12 & 13 days post-completion \\
\hline \multirow[t]{3}{*}{ Oxaliplatin-6 } & 16 & 187 & 6 & Cycle 1 \\
\hline & 17 & 280 & 11 & Cycle 6 \\
\hline & 18 & 196 & 20 & 27 days post-completion \\
\hline \multirow[t]{3}{*}{ Oxaliplatin-7 } & 19 & 208 & 51 & Cycle 1 \\
\hline & 20 & 268 & 10 & Cycle 7 \\
\hline & 21 & 114 & 4 & 48 days post-completion \\
\hline \multirow[t]{3}{*}{ Oxaliplatin-8 } & 22 & 130 & 7 & Cycle 1 \\
\hline & 23 & 142 & 4 & Cycle 2 \\
\hline & 24 & 183 & 2 & Cycle 3 \\
\hline \multirow[t]{3}{*}{ Cisplatin-9 } & 25 & 220 & 15 & Cycle 1 \\
\hline & 26 & 353 & 5 & Cycle 3 \\
\hline & 27 & 901 & 42 & 3 days post-completion \\
\hline \multirow[t]{3}{*}{ Oxaliplatin-10 } & 28 & 1 & 2 & Pre-treatment \\
\hline & 29 & 236 & 20 & Cycle 6 \\
\hline & 30 & 125 & 9 & 35 days post-completion \\
\hline \multirow[t]{2}{*}{ Cisplatin-11 } & 31 & 450 & 23 & Cycle 1 \\
\hline & 32 & 671 & 87 & 10 days post-completion \\
\hline \multirow[t]{2}{*}{ Oxaliplatin-12 } & 33 & 133 & 13 & Cycle 1 \\
\hline & 34 & 175 & 15 & 25 days post-completion \\
\hline
\end{tabular}




\begin{tabular}{|c|c|c|c|c|}
\hline \multirow[t]{2}{*}{ Oxaliplatin-13 } & 35 & 117 & 7 & Cycle 1 \\
\hline & 36 & 255 & 9 & Cycle 3 \\
\hline \multirow[t]{2}{*}{ Oxaliplatin-14 } & 37 & 188 & 8 & Cycle 5 \\
\hline & 38 & 272 & 10 & 14 days post-completion \\
\hline \multirow[t]{2}{*}{ Cisplatin-15 } & 39 & 449 & 29 & Cycle 1 \\
\hline & 40 & 118 & 16 & 45 days post-completion \\
\hline \multirow[t]{2}{*}{ Oxaliplatin-16 } & 41 & 74 & 3 & Cycle 1 \\
\hline & 42 & 139 & 13 & Cycle 4 \\
\hline \multirow[t]{3}{*}{ Oxaliplatin-17 } & 43 & 168 & 8 & Cycle 1 \\
\hline & 44 & 163 & 0 & Cycle 2 \\
\hline & 45 & 179 & 12 & 28 days post-completion \\
\hline \multirow[t]{3}{*}{ Oxaliplatin-18 } & 46 & 107 & 11 & Cycle 1 \\
\hline & 47 & 207 & 10 & Cycle 6 \\
\hline & 48 & 259 & 8 & 13 days post- completion \\
\hline \multirow[t]{3}{*}{ Oxaliplatin-19 } & 49 & 0 & 0 & Baseline \\
\hline & 50 & 284 & 17 & Cycle 6 \\
\hline & 51 & 41 & 3 & 55 days post-completion \\
\hline \multirow[t]{2}{*}{ Oxaliplatin-20 } & 52 & 144 & 22 & Cycle 1 \\
\hline & 53 & 448 & 16 & Cycle 11 \\
\hline \multirow[t]{3}{*}{ Oxaliplatin-21 } & 54 & 146 & 11 & Cycle 1 \\
\hline & 55 & 348 & 18 & Cycle 6 \\
\hline & 56 & 505 & 1 & 14 days post-completion \\
\hline \multirow[t]{3}{*}{ Cisplatin-22 } & 57 & 821 & 83 & Cycle 1 \\
\hline & 58 & 1449 & 187 & Cycle 4 \\
\hline & 59 & 29 & 8 & $\begin{array}{l}157 \text { days post- } \\
\text { completion }\end{array}$ \\
\hline \multirow[t]{3}{*}{ Oxaliplatin-23 } & 60 & 127 & 0 & Cycle 1 \\
\hline & 61 & 426 & 26 & Cycle 6 \\
\hline & 62 & 154 & 6 & 28 days post-completion \\
\hline \multirow[t]{3}{*}{ Oxaliplatin-24 } & 63 & 142 & 24 & Cycle 1 \\
\hline & 64 & 291 & 35 & Cycle 6 \\
\hline & 65 & 460 & 6 & Cycle 11 \\
\hline \multirow[t]{3}{*}{ Oxaliplatin-25 } & 66 & 167 & 3 & Cycle 1 \\
\hline & 67 & 339 & 38 & Cycle 7 \\
\hline & 68 & 120 & 0 & 41 days post-completion \\
\hline \multirow[t]{2}{*}{ Cisplatin-26 } & 69 & 335 & 25 & Cycle 1 \\
\hline & 70 & 1205 & 38 & 3 days post-completion \\
\hline \multirow[t]{3}{*}{ Oxaliplatin-27 } & 71 & 120 & 9 & Cycle 1 \\
\hline & 72 & 260 & 33 & Cycle 6 \\
\hline & 73 & 387 & 12 & Cycle 11 \\
\hline
\end{tabular}




\section{Monitoring platinum drugs in cancer patients}

Table S5. ICP-MS data used for LDA in Figure 5. Pt(II) concentration values are calculated by dividing the original ICP-MS determined concentration by a dilution factor.

\begin{tabular}{|c|c|c|c|}
\hline Grouping Variable & $\begin{array}{l}\text { Cisplatin samples- } \\
\mathrm{Pt}(\mathrm{II}) \text { concentration } \\
(\mathrm{ppb})\end{array}$ & Grouping Variable & $\begin{array}{l}\text { Oxaliplatin samples- } \\
\text { Pt(II) concentration } \\
(\mathrm{ppb})\end{array}$ \\
\hline 1 & 15 & 3 & 20 \\
\hline 1 & 59 & 3 & 60 \\
\hline 1 & 110 & 3 & 113 \\
\hline 1 & 167 & 3 & 146 \\
\hline 1 & 176 & 3 & 203 \\
\hline 2 & 225 & 4 & 213 \\
\hline 2 & 225 & 4 & 224 \\
\hline 2 & 335 & 4 & 230 \\
\hline 2 & 411 & 4 & 252 \\
\hline 2 & 451 & 4 & \\
\hline
\end{tabular}

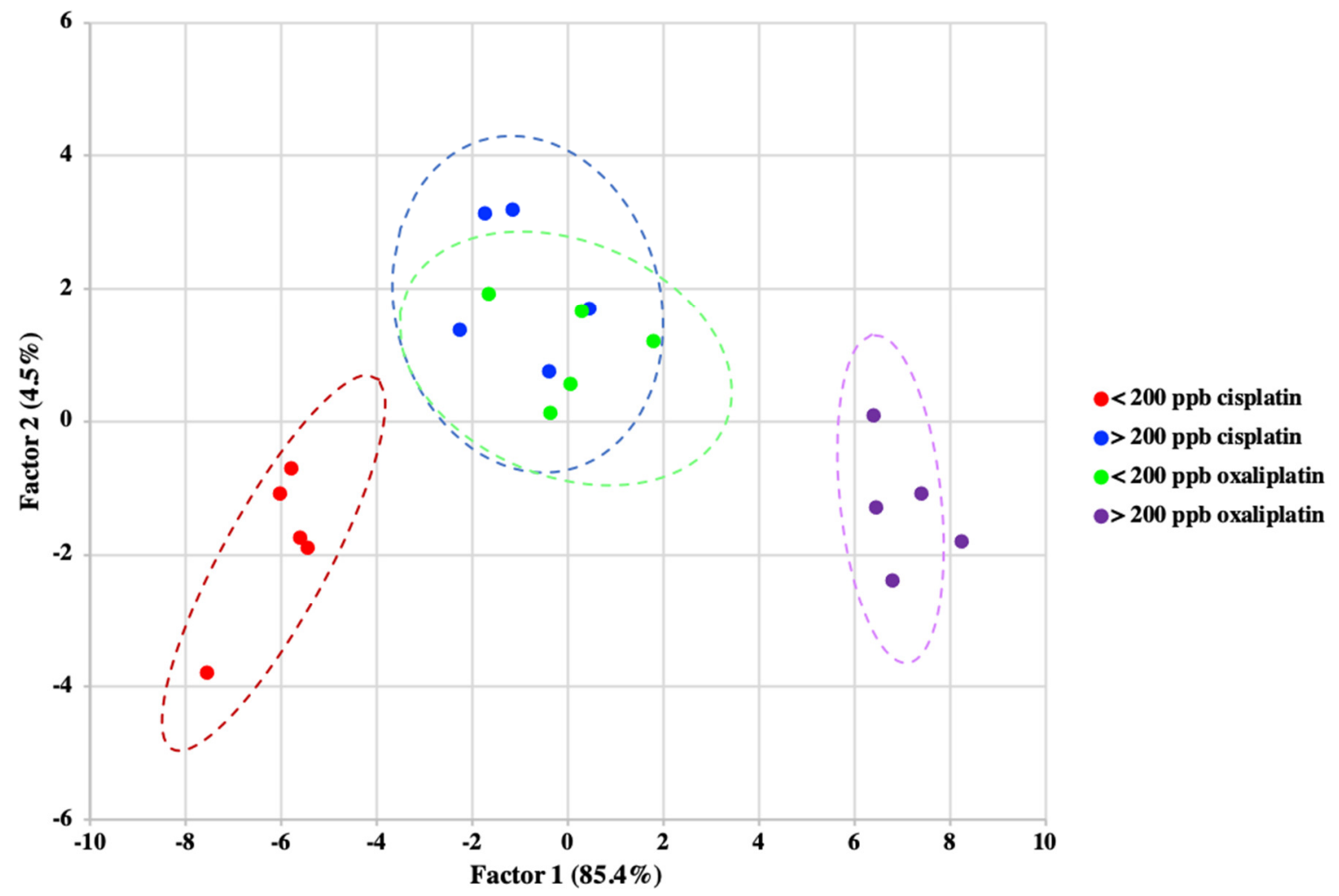

Figure S13. Two-dimensional LDA score plot of the fluorescence response pattern (14 fluorescence variables, $\left.\left(\mathrm{I} / \mathrm{I}_{0}\right)\right)$ of S1-6 $(10 \mu \mathrm{M})$ in DMF $(4 \% \mathrm{v} / \mathrm{v})$ with a range of cisplatin and oxaliplatin samples patient samples (50\% v/v) diluted in PBS buffer $(20 \mathrm{mM}, \mathrm{pH} 7.4,46 \%$ $\mathrm{v} / \mathrm{v}$ ) with $95 \%$ confidence ellipses. 


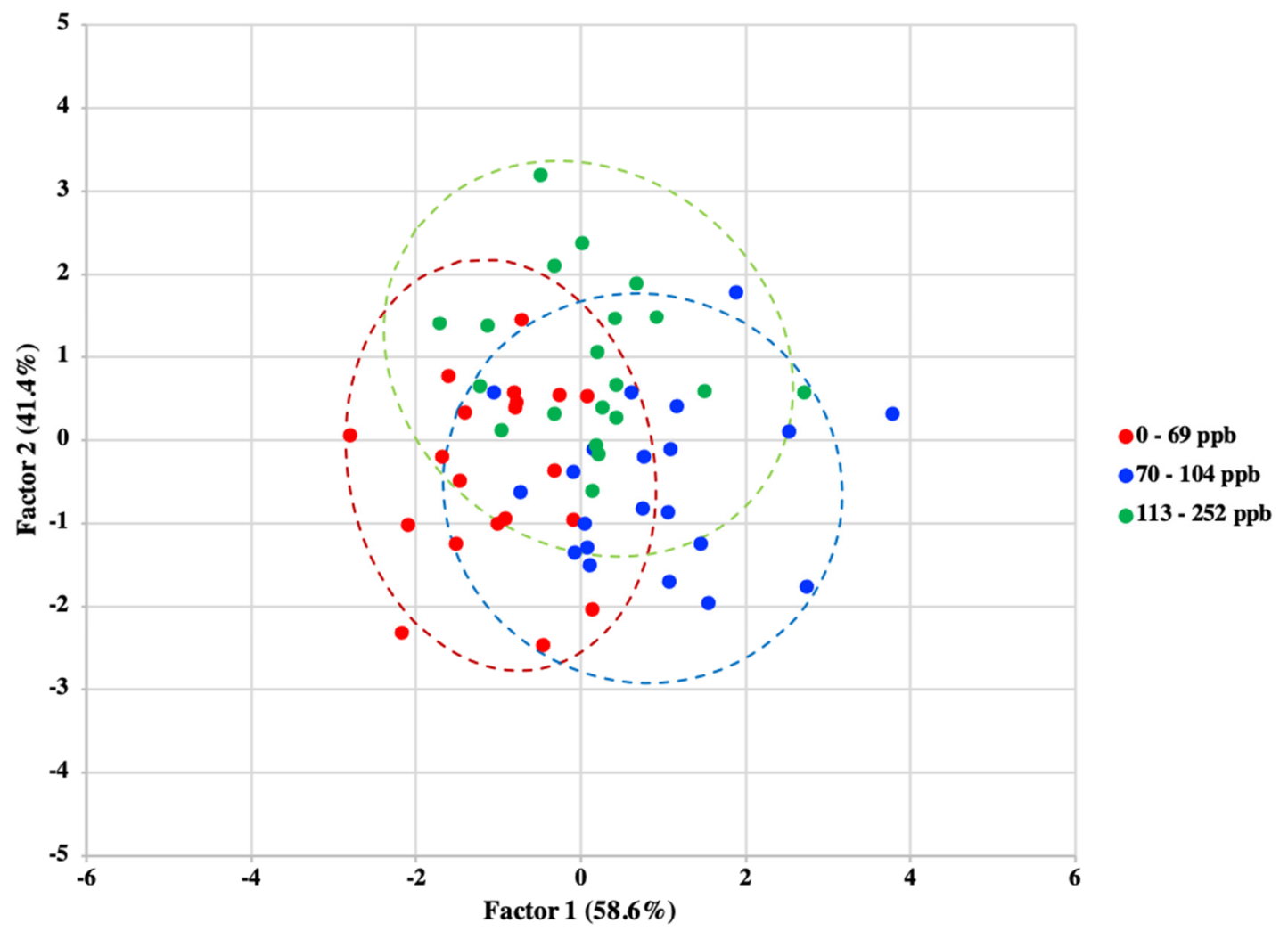

Figure S14. Two-dimensional LDA score plot of the fluorescence response pattern (14 fluorescence variables, $\left.\left(\mathrm{I} / \mathrm{I}_{0}\right)\right)$ of S1-6 $(10 \mu \mathrm{M})$ in DMF $(4 \% \mathrm{v} / \mathrm{v})$ with all 61 clinical plasma samples (figure S4) of patients undergoing oxaliplatin chemotherapy $(50 \% \mathrm{v} / \mathrm{v})$ diluted in PBS buffer (20 mM, pH 7.4, $46 \%$ v/v) with $95 \%$ confidence ellipses.

Table S6. ICP-MS data used for LDA in figure 6. Pt(II) concentration values are calculated by dividing the original ICP-MS determined concentration by a dilution factor. Grouping variables 1, 2 and 3 correspond to low, medium and high data respectively.

\begin{tabular}{|c|c|c|c|}
\hline Grouping Variable & $\begin{array}{l}\text { Oxaliplatin samples- } \\
\mathrm{Pt}(\mathrm{II}) \text { concentration } \\
(\mathrm{ppb})\end{array}$ & Grouping Variable & $\begin{array}{l}\text { Oxaliplatin samples- } \\
\text { Pt(II) concentration } \\
(\mathrm{ppb})\end{array}$ \\
\hline 1 & 37 & 2 & 98 \\
\hline 1 & 53 & 2 & 103 \\
\hline 1 & 54 & 2 & 104 \\
\hline 1 & 57 & 2 & 113 \\
\hline 1 & 59 & 3 & 140 \\
\hline 1 & 60 & 3 & 142 \\
\hline 1 & 60 & 3 & 146 \\
\hline 1 & 61 & 3 & 170 \\
\hline 1 & 62 & 3 & 194 \\
\hline 1 & 63 & 3 & 203 \\
\hline 2 & 90 & 3 & 213 \\
\hline 2 & 92 & 3 & 224 \\
\hline 2 & 93 & 3 & 230 \\
\hline 2 & 93 & 3 & \\
\hline 2 & 94 & & 2 \\
\hline
\end{tabular}


Table S7. ICP-MS data used for LDA in Figure S13. Pt(II) concentration values are calculated by dividing the original ICP-MS determined concentration by a dilution factor. Grouping variables 1, 2 and 3 correspond to low, medium and high data respectively.

\begin{tabular}{|c|c|c|c|}
\hline Grouping Variable & $\begin{array}{l}\text { Oxaliplatin } \\
\text { concentration }(\mathrm{ppb})\end{array}$ & Grouping Variable & $\begin{array}{l}\text { Oxaliplatin } \\
\text { concentration }(\mathrm{ppb})\end{array}$ \\
\hline 1 & 37 & Unknown & 93 \\
\hline Unknown & 37 & 2 & 94 \\
\hline 1 & 53 & 2 & 98 \\
\hline 1 & 54 & 2 & 103 \\
\hline Unknown & 57 & Unknown & 104 \\
\hline 1 & 59 & 2 & 113 \\
\hline 1 & 60 & 2 & 140 \\
\hline Unknown & 60 & 3 & 142 \\
\hline 1 & 61 & Unknown & 146 \\
\hline 1 & 62 & 3 & 170 \\
\hline Unknown & 63 & 3 & 174 \\
\hline 1 & 63 & Unknown & 194 \\
\hline 1 & 64 & 3 & 203 \\
\hline Unknown & 65 & 3 & 213 \\
\hline 2 & 88 & 3 & 224 \\
\hline Unknown & 90 & Unknown & 252 \\
\hline 2 & 92 & 3 & 3 \\
\hline 2 & 93 & & 30 \\
\hline
\end{tabular}

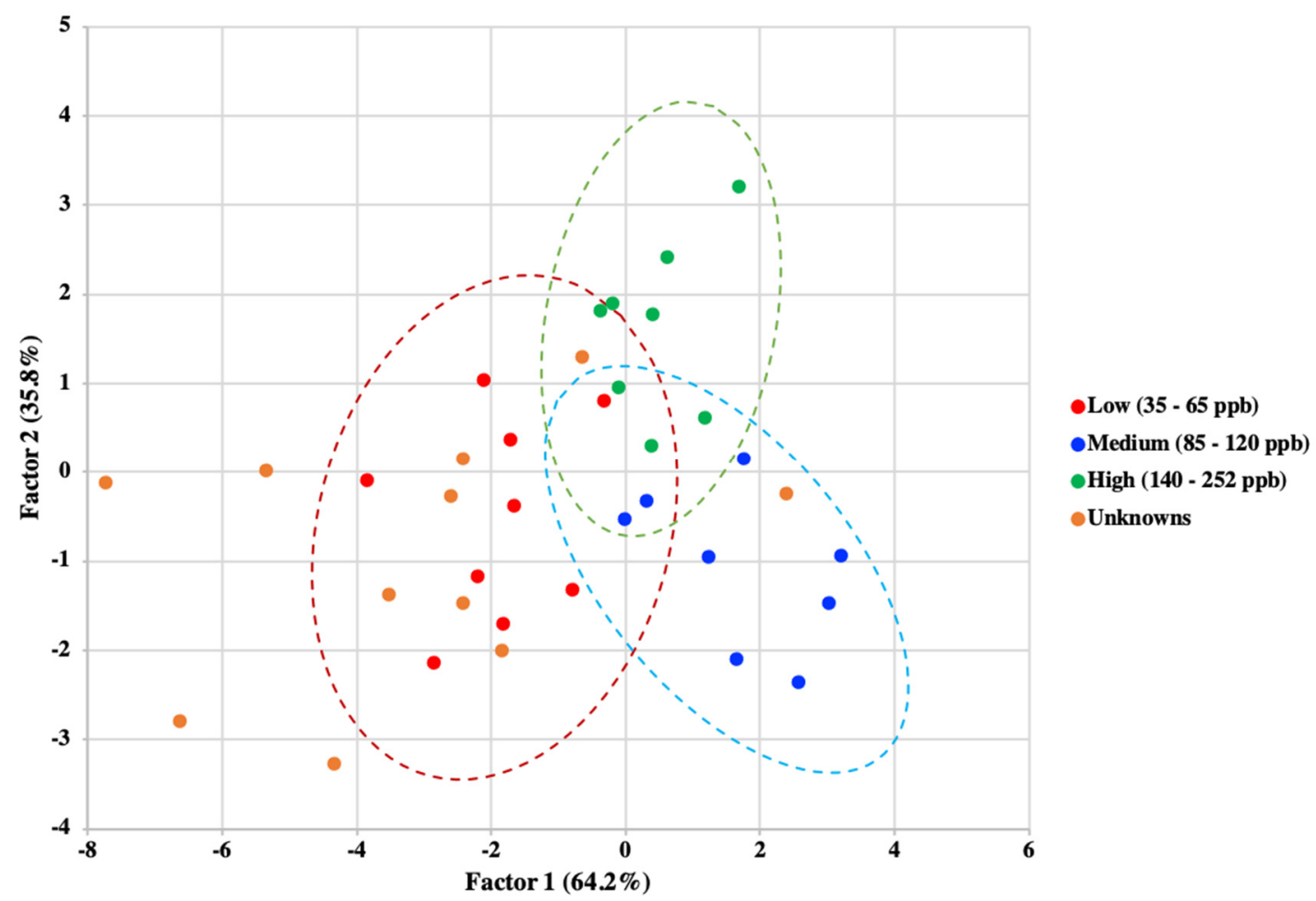

Figure S15. Two-dimensional LDA score plot of the fluorescence response pattern (14 fluorescence variables, $\left.\left(\mathrm{I} / \mathrm{I}_{0}\right)\right)$ of S1-6 $(10 \mu \mathrm{M})$ in DMF $(4 \% \mathrm{v} / \mathrm{v})$ with all 36 clinical plasma samples of patients undergoing oxaliplatin chemotherapy $(50 \% \mathrm{v} / \mathrm{v})$ diluted in PBS buffer (20 $\mathrm{mM}, \mathrm{pH} 7.4,46 \%$ v/v) with $95 \%$ confidence ellipses. 
a)

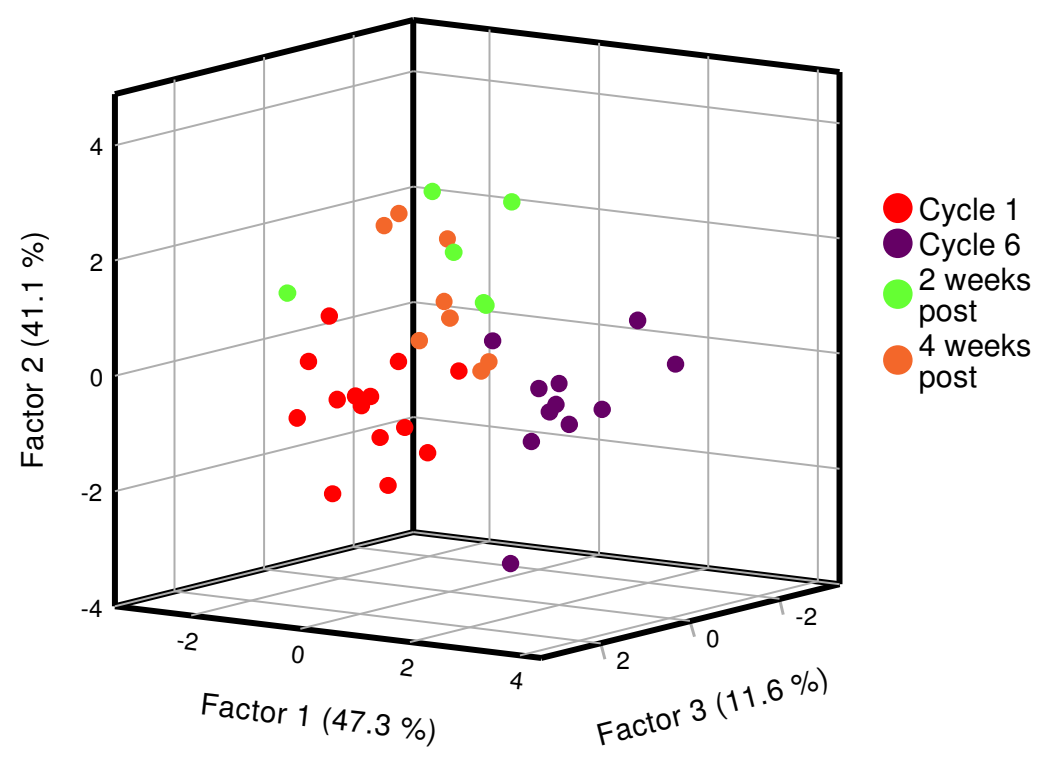

b)

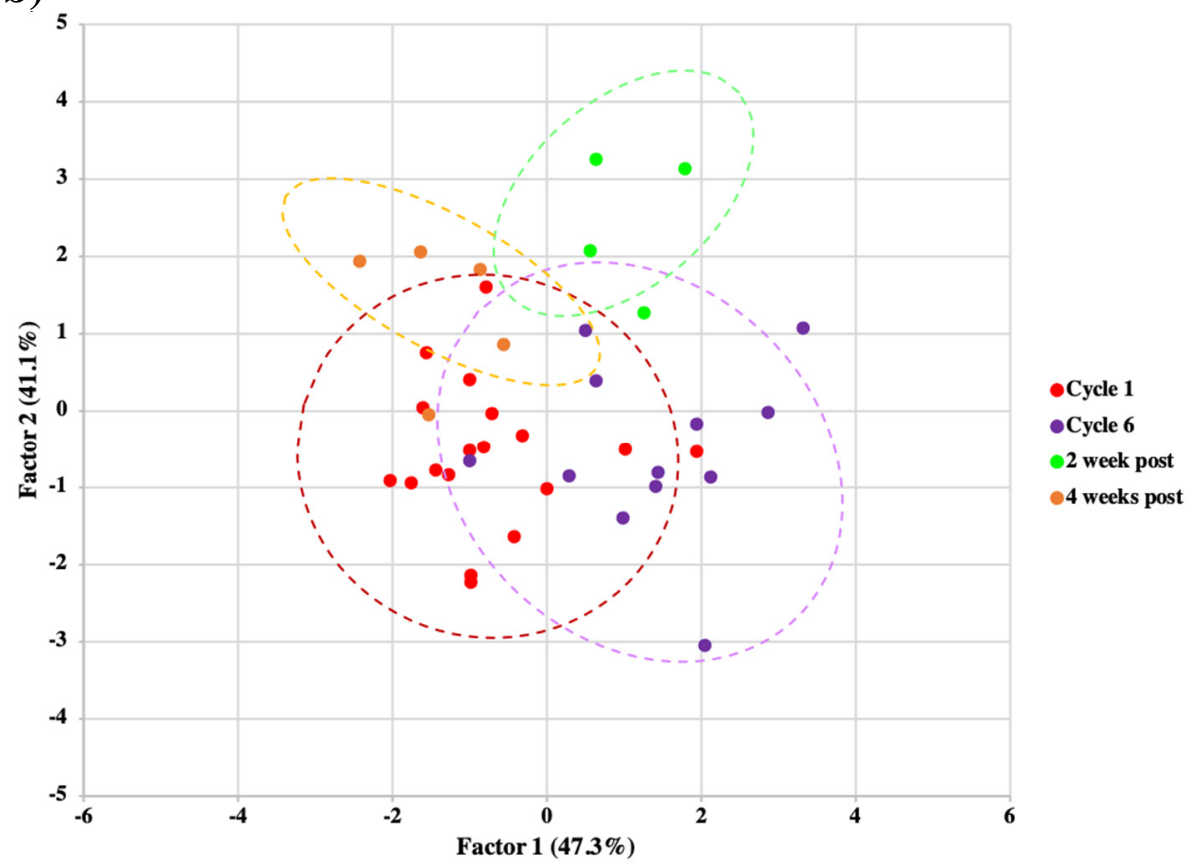

Figure S16. The fluorescence response pattern (14 fluorescence variables, $\left.\left(\mathrm{I} / \mathrm{I}_{0}\right)\right)$ of S1-6 (10 $\mu \mathrm{M})$ in DMF $(4 \% \mathrm{v} / \mathrm{v})$ with all 39 clinical plasma samples of patients undergoing oxaliplatin chemotherapy (50\% v/v) diluted in PBS buffer $(20 \mathrm{mM}, \mathrm{pH} 7.4,46 \% \mathrm{v} / \mathrm{v})$ presented as a) a three-dimensional LDA score plot and b) a two-dimensional LDA score plot with $95 \%$ confidence ellipses.

Table S8. Treatment time point used for LDA in Figure S14.

\begin{tabular}{|l|l|l|}
\hline Treatment Stage & Number of Samples & Grouping Variable \\
\hline Cycle 1 & 18 & 1 \\
\hline Cycle 6 & 12 & 2 \\
\hline 2 weeks post-treatment & 4 & 3 \\
\hline 4 weeks post-treatment & 5 & 4 \\
\hline
\end{tabular}




\section{LDA jackknife validation}

Using LDA, the accuracy of each array system was evaluated using a jackknife validation routine. In jackknife analysis, cases were systematically removed one at a time, LDA was reperformed on the reduced set and the omitted sample was reclassified to determine if it is allocated into the correct class. The results are presented in a classification matrix table, with correct classifications on the main diagonal in red and misclassifications on the off diagonal. The cross-validated classification accuracy is then calculated using the average of all the individual classifications and highlighted in red in the bottom right cell.

Table S9. Results from jackknife analysis on the LDA classification of 9 metals ions $(50 \mu \mathrm{M})$.

\begin{tabular}{|l|l|l|l|l|l|l|l|l|l|l|}
\hline Metals & Ni (II) & Cu (II) & Zn (II) & Fe (III) & Co (II) & Pb (II) & Cd (II) & Hg (II) & Pt (II) & \% correct \\
\hline Ni (II) & 4 & 1 & 0 & 0 & 0 & 0 & 0 & 0 & 0 & 80 \\
\hline Cu (II) & 1 & 4 & 0 & 0 & 0 & 0 & 0 & 0 & 0 & 80 \\
\hline $\mathbf{Z n}$ (II) & 0 & 0 & 5 & 0 & 0 & 0 & 0 & 0 & 0 & 100 \\
\hline Fe (III) & 0 & 0 & 0 & 4 & 0 & 1 & 0 & 0 & 0 & 80 \\
\hline Co (II) & 0 & 1 & 0 & 0 & 4 & 0 & 0 & 0 & 0 & 80 \\
\hline Pb (II) & 0 & 0 & 0 & 0 & 0 & 5 & 0 & 0 & 0 & 100 \\
\hline Cd (II) & 0 & 0 & 0 & 0 & 0 & 0 & 5 & 0 & 0 & 100 \\
\hline Hg (II) & 0 & 0 & 0 & 0 & 0 & 0 & 0 & 5 & 0 & 100 \\
\hline Pt (II) & 0 & 0 & 0 & 0 & 0 & 0 & 0 & 0 & 5 & 100 \\
\hline Total & 5 & 6 & 5 & 4 & 4 & 6 & 5 & 5 & 5 & $91 \%$ \\
\hline
\end{tabular}

Table S10. Results from jackknife analysis on the LDA classification of 8 platinum complexes $(200 \mu \mathrm{M})$, all grouped.

\begin{tabular}{|c|c|c|c|c|c|c|c|c|c|}
\hline Complex & Cisp & Transp & $\mathrm{PtCl}_{2}(\mathrm{en})$ & Phenanth & $\begin{array}{l}\mathrm{PtCl}\left(\mathrm{NH}_{3}\right) \\
\end{array}$ & $\mathrm{K}_{2}\left[\mathrm{PtCl}_{4}\right]$ & Oxali & Pyri & $\begin{array}{l}\% \\
\text { correct }\end{array}$ \\
\hline Cisplatin & 4 & 0 & 1 & 0 & 0 & 0 & 0 & 0 & 80 \\
\hline Transplatin & 0 & 4 & 0 & 0 & 0 & 1 & 0 & 0 & 80 \\
\hline$\left[\mathbf{P t C l}_{2}(\mathbf{e n})\right]$ & 1 & 0 & 2 & 0 & 1 & 0 & 1 & 0 & 40 \\
\hline Phenanthriplatin & 0 & 0 & 0 & 4 & 0 & 0 & 0 & 1 & 80 \\
\hline$\left[\mathrm{PtCl}\left(\mathrm{NH}_{3}\right)_{3}\right] \mathrm{Cl}$ & 1 & 1 & 1 & 0 & 2 & 0 & 0 & 0 & 40 \\
\hline $\mathrm{K}_{2}\left[\mathrm{PtCl}_{4}\right]$ & 0 & 1 & 0 & 0 & 0 & 4 & 0 & 0 & 80 \\
\hline Oxaliplatin & 0 & 0 & 0 & 0 & 0 & 0 & 5 & 0 & 100 \\
\hline Pyriplatin & 0 & 0 & 0 & 0 & 0 & 0 & 0 & 5 & 100 \\
\hline Total & 6 & 6 & 4 & 4 & 3 & 5 & 6 & 6 & $75 \%$ \\
\hline
\end{tabular}


Table S11. Results from jackknife analysis on the LDA classification of spiked cisplatin samples $(0.5-5 \mu \mathrm{M})$ using 6 fluorescence measurements.

\begin{tabular}{|l|l|l|l|l|l|}
\hline $\begin{array}{l}\text { Cisplatin } \\
\text { concentration }\end{array}$ & $\mathbf{0 . 5} \boldsymbol{\mu M}$ & $\mathbf{1} \boldsymbol{\mu M}$ & $\mathbf{2} \boldsymbol{\mu M}$ & $\mathbf{5} \boldsymbol{\mu M}$ & \% correct \\
\hline $\mathbf{0 . 5} \boldsymbol{\mu M}$ & 0 & 2 & 3 & 0 & 0 \\
\hline $\mathbf{1} \boldsymbol{\mu M}$ & 2 & 3 & 0 & 0 & 60 \\
\hline $\mathbf{2} \boldsymbol{\mu M}$ & 2 & 1 & 0 & 1 & 0 \\
\hline $\mathbf{5} \boldsymbol{\mu M}$ & 1 & 0 & 1 & 3 & 60 \\
\hline Total & 5 & 6 & 4 & 4 & 31.6 \\
\hline
\end{tabular}

Table S12. Results from jackknife analysis on the LDA classification of spiked oxaliplatin samples $(0.5-5 \mu \mathrm{M})$ using 6 fluorescence measurements.

\begin{tabular}{|l|l|l|l|l|l|}
\hline $\begin{array}{l}\text { Oxaliplatin } \\
\text { concentration }\end{array}$ & $\mathbf{0 . 5} \boldsymbol{\mu M}$ & $\mathbf{1} \boldsymbol{\mu M}$ & $\mathbf{2} \boldsymbol{\mu M}$ & $\mathbf{5} \boldsymbol{\mu M}$ & \% correct \\
\hline $\mathbf{0 . 5} \boldsymbol{\mu M}$ & 0 & 2 & 2 & 1 & 0 \\
\hline $\mathbf{1} \boldsymbol{\mu M}$ & 1 & 3 & 0 & 1 & 60 \\
\hline $\mathbf{2} \boldsymbol{\mu M}$ & 1 & 2 & 0 & 2 & 0 \\
\hline $\mathbf{5} \boldsymbol{\mu M}$ & 1 & 1 & 0 & 3 & 60 \\
\hline Total & 3 & 8 & 2 & 7 & 30 \\
\hline
\end{tabular}

Table S13. Results from jackknife analysis on the LDA classification of spiked cisplatin samples $(0.5-5 \mu \mathrm{M})$ using 14 fluorescence measurements.

\begin{tabular}{|l|l|l|l|l|l|}
\hline $\begin{array}{l}\text { Cisplatin } \\
\text { concentration }\end{array}$ & $\mathbf{0 . 5} \boldsymbol{\mu M}$ & $\mathbf{1} \boldsymbol{\mu M}$ & $\mathbf{2} \boldsymbol{\mu M}$ & $\mathbf{5} \boldsymbol{\mu M}$ & \% correct \\
\hline $\mathbf{0 . 5} \boldsymbol{\mu M}$ & 3 & 0 & 2 & 0 & 60 \\
\hline $\mathbf{1} \boldsymbol{\mu M}$ & 0 & 3 & 1 & 1 & 60 \\
\hline $\mathbf{2} \boldsymbol{\mu M}$ & 1 & 1 & 2 & 0 & 40 \\
\hline $\mathbf{5} \boldsymbol{\mu M}$ & 1 & 0 & 1 & 3 & 60 \\
\hline Total & 5 & 4 & 6 & 4 & 57.9 \\
\hline
\end{tabular}


Table S14. Results from jackknife analysis on the LDA classification of spiked oxaliplatin samples $(0.5-5 \mu \mathrm{M})$ using 14 fluorescence measurements.

\begin{tabular}{|l|l|l|l|l|l|}
\hline $\begin{array}{l}\text { Oxaliplatin } \\
\text { concentration }\end{array}$ & $\mathbf{0 . 5} \boldsymbol{\mu M}$ & $\mathbf{1} \boldsymbol{\mu M}$ & $\mathbf{2} \boldsymbol{\mu M}$ & $\mathbf{5} \boldsymbol{\mu M}$ & \% correct \\
\hline $\mathbf{0 . 5} \boldsymbol{\mu M}$ & 1 & 1 & 3 & 0 & 20 \\
\hline $\mathbf{1} \boldsymbol{\mu M}$ & 0 & 4 & 0 & 1 & 80 \\
\hline $\mathbf{2} \boldsymbol{\mu M}$ & 2 & 0 & 3 & 0 & 60 \\
\hline $\mathbf{5} \boldsymbol{\mu M}$ & 0 & 0 & 0 & 5 & 100 \\
\hline Total & 5 & 4 & 6 & 4 & 65 \\
\hline
\end{tabular}

Table S15. Results from jackknife analysis on the LDA classification of both cisplatin and oxaliplatin spiked samples $(0.5-5 \mu \mathrm{M})$ using 14 fluorescence measurements.

\begin{tabular}{|l|l|l|l|l|l|}
\hline $\begin{array}{l}\text { Platinum } \\
\text { concentration }\end{array}$ & $\begin{array}{l}\text { Cisplatin 0.5 } \\
\mathbf{- 1} \boldsymbol{\mu M}\end{array}$ & $\begin{array}{l}\text { Cisplatin 2 - } \\
\mathbf{5} \boldsymbol{\mu M}\end{array}$ & $\begin{array}{l}\text { Oxaliplatin } \\
\mathbf{0 . 5}-\mathbf{\mu M}\end{array}$ & $\begin{array}{l}\text { Oxaliplatin 2 } \\
\mathbf{- 5} \boldsymbol{\mu M}\end{array}$ & \% correct \\
\hline Cisplatin 0.5 -1 $\boldsymbol{\mu M}$ & 8 & 2 & 0 & 0 & 80 \\
\hline Cisplatin 2 -5 $\boldsymbol{\mu M}$ & 4 & 5 & 0 & 0 & 55.6 \\
\hline Oxaliplatin 0.5 -1 $\boldsymbol{\mu M}$ & 0 & 0 & 9 & 1 & 90 \\
\hline Oxaliplatin 2 -5 $\boldsymbol{\mu M}$ & 0 & 1 & 2 & 7 & 70 \\
\hline Total & 12 & 8 & 11 & 8 & 74.4 \\
\hline
\end{tabular}

Table S16. Results from jackknife analysis on the LDA classification of clinical cisplatin and oxaliplatin samples $(0.5-5 \mu \mathrm{M})$ using 14 fluorescence measurements.

\begin{tabular}{|c|c|c|c|c|c|}
\hline $\begin{array}{l}\text { Platinum } \\
\text { concentration }\end{array}$ & $\begin{array}{l}\text { Cisplatin } \\
<200 \text { ppb }\end{array}$ & $\begin{array}{l}\text { Cisplatin } \\
>200 \text { ppb }\end{array}$ & $\begin{array}{l}\text { Oxaliplatin } \\
<200 \text { ppb }\end{array}$ & $\begin{array}{l}\text { Oxaliplatin } \\
>200 \text { ppb }\end{array}$ & $\%$ correct \\
\hline $\begin{array}{l}\text { Cisplatin } \\
<200 \text { ppb }\end{array}$ & 1 & 1 & 2 & 1 & 20 \\
\hline $\begin{array}{l}\text { Cisplatin } \\
>200 \text { ppb }\end{array}$ & 2 & 1 & 0 & 2 & 20 \\
\hline $\begin{array}{l}\text { Oxaliplatin } \\
<200 \text { ppb }\end{array}$ & 1 & 1 & 2 & 1 & 40 \\
\hline $\begin{array}{l}\text { Oxaliplatin } \\
>200 \text { ppb }\end{array}$ & 1 & 1 & 1 & 2 & 40 \\
\hline Total & 5 & 4 & 5 & 6 & 30 \\
\hline
\end{tabular}


Table S17. Results from jackknife analysis on the LDA classification of clinical oxaliplatin samples $(0-252 \mathrm{ppb})$ using 14 fluorescence measurements.

\begin{tabular}{|l|l|l|l|l|}
\hline $\begin{array}{l}\text { Oxaliplatin } \\
\text { concentration }\end{array}$ & $\mathbf{0}-\mathbf{6 9} \mathbf{p p b}$ & $\mathbf{7 0}-\mathbf{1 0 4} \mathbf{p p b}$ & $\mathbf{1 1 3}-\mathbf{2 5 2} \mathbf{~ p p b}$ & \% correct \\
\hline $\mathbf{0}-\mathbf{6 9} \mathbf{~ p p b}$ & 9 & 4 & 7 & 45 \\
\hline $\mathbf{7 0 - 1 0 4} \mathbf{~ p p b}$ & 7 & 10 & 4 & 48 \\
\hline $\mathbf{1 1 3}-\mathbf{2 5 2} \mathbf{p p b}$ & 4 & 9 & 7 & 35 \\
\hline Total & 20 & 23 & 18 & 42.6 \\
\hline
\end{tabular}

Table S18. Results from jackknife analysis on the LDA classification of clinical oxaliplatin samples $(35-230 \mathrm{ppb})$ using 14 fluorescence measurements.

\begin{tabular}{|l|l|l|l|l|}
\hline $\begin{array}{l}\text { Oxaliplatin } \\
\text { concentration }\end{array}$ & $\mathbf{3 5}-\mathbf{6 5} \mathbf{p p b}$ & $\mathbf{9 0}-\mathbf{1 2 0} \mathbf{~ p p b}$ & $\mathbf{1 4 0}-\mathbf{2 3 0} \mathbf{~ p p b}$ & \% correct \\
\hline $\mathbf{3 5}-\mathbf{6 5} \mathbf{~ p p b}$ & 6 & 2 & 2 & 60 \\
\hline $\mathbf{9 0 - 1 2 0} \mathbf{~ p p b}$ & 3 & 5 & 2 & 50 \\
\hline $\mathbf{1 4 0}-\mathbf{2 3 0} \mathbf{p p b}$ & 5 & 2 & 3 & 30 \\
\hline Total & 14 & 9 & 7 & 46.7 \\
\hline
\end{tabular}

Table S19. Results from jackknife analysis on the LDA classification of clinical oxaliplatin samples $(35-230 \mathrm{ppb})$ using 14 fluorescence measurements.

\begin{tabular}{|l|l|l|l|l|l|}
\hline $\begin{array}{l}\text { Oxaliplatin } \\
\text { concentration }\end{array}$ & Cycle 1 & Cycle 6 & 2 weeks post & 4 weeks post & \% correct \\
\hline Cycle 1 & 10 & 4 & 1 & 3 & 55 \\
\hline Cycle 6 & 3 & 6 & 2 & 1 & 50 \\
\hline 2 weeks post & 0 & 1 & 2 & 1 & 50 \\
\hline 4 weeks post & 3 & 0 & 2 & 0 & 0 \\
\hline Total & 16 & 11 & 7 & 5 & 46.2 \\
\hline
\end{tabular}




\section{References}

(1) Shen, C.; Harris, B. D. W.; Dawson, L. J.; Charles, K. A.; Hambley, T. W.; New, E. J. Fluorescent Sensing of Monofunctional Platinum Species. Chem. Commun. 2015, 51, 6312-6314.

(2) Kolanowski, J. L.; Dawson, L. J.; Mitchell, L.; Lim, Z.; Graziotto, M. E.; Filipek, W. K.; Hambley, T. W.; New, E. J. A Fluorescent Probe for Investigating Metabolic Stability of Active Transplatin Analogues. Sensors Actuators, B Chem. 2018, 255, 2721-2724.

(3) Shi, W.; Ma, H. Rhodamine B Thiolactone: A Simple Chemosensor for $\mathrm{Hg} 2+$ in Aqueous Media. Chem. Commun. 2008, No. 16, 1856-1858.

(4) Kaur, A.; Haghighatbin, M. A.; Hogan, C. F.; New, E. J. A FRET-Based Ratiometric Redox Probe for Detecting Oxidative Stress by Confocal Microscopy, FLIM and Flow Cytometry. Chem. Commun. 2015, 51 (52), 10510-10513.

(5) Gerritz, S. W.; Zhai, W.; Shi, S.; Zhu, S.; Toyn, J. H.; Meredith, J. E.; Iben, L. G.; Burton, C. R.; Albright, C. F.; Good, A. C.; Tebben, A. J.; Muckelbauer, J. K.; Camac, D. M.; Metzler, W.; Cook, L. S.; Padmanabha, R.; Lentz, K. A.; Sofia, M. J.; Poss, M. A.; MacOr, J. E.; Thompson, L. A. Acyl Guanidine Inhibitors of $\beta$-Secretase (BACE1): Optimization of a Micromolar Hit to a Nanomolar Lead via Iterative Solid- and Solution-Phase Library Synthesis. J. Med. Chem. 2012, 55 (21), 9208-9223. 